\title{
Transient and Stable Silver Clusters Induced by Radiolysis in Methanol
}

\author{
M. Mostafavi,* G. R. Dey, ${ }^{\dagger}$ L. François, and J. Belloni \\ Laboratoire de Chimie Physique, UMR CNRS-UPS 8000, Bât. 349, Université Paris-Sud, \\ 91405, Orsay, France
}

Received: November 19, 2001; In Final Form: July 2, 2002

\begin{abstract}
The optical absorption spectra of $\mathrm{Ag}^{0}, \mathrm{Ag}_{2}{ }^{+}$, transient oligomers, and stable clusters were studied in deaerated methanol by pulse and $\gamma$-radiolysis methods and compared with data obtained from studies using other solvents. From the decay of $\mathrm{e}^{-}$solv at $620 \mathrm{~nm}$, the formation rate constant of $\mathrm{Ag}^{0}$ was determined to be $k\left(\mathrm{e}^{-}\right.$solv $\left.+\mathrm{Ag}^{+}\right)$ $=(2.6 \pm 0.6) \times 10^{10} \mathrm{M}^{-1} \mathrm{~s}^{-1}$. The coalescence rate of transient oligomers is particularly slow and the growth process is not completed within $2 \mathrm{~s}$ after the pulse. The surface plasmon band of stable clusters obtained by $\gamma$-radiolysis in methanol is intense and sharp $\left(\epsilon_{385} \mathrm{~nm}=1.8 \times 10^{4} \mathrm{M}^{-1} \mathrm{~cm}^{-1}\right)$. The clusters are readily oxidized by oxygen. By adding methyl viologen $\mathrm{MV}^{2+}$ to the solution containing stable silver clusters, the blue color of $\mathrm{MV}^{+} \bullet$ is transitorily observed, and the small clusters are developed into larger ones. Similarly, by pulse radiolysis of a mixture of silver cations and $\mathrm{MV}^{2+}$, silver atoms and $\mathrm{MV}^{+\bullet}$ are formed immediately through solvated electron scavenging, but subsequently additional $\mathrm{MV}^{+\bullet}$ are produced by reduction of $\mathrm{MV}^{2+}$ by $\mathrm{Ag}^{0}$ and small oligomers. In a further step, $\mathrm{MV}^{+\bullet}$ radicals reduce $\mathrm{Ag}^{+}$cations adsorbed on large clusters and let them develop eventually to larger sizes. The general mechanism of the methanol radiolysis is revisited on the basis of electron and radical scavenging by $\mathrm{Ag}^{+}$and silver clusters, and values of the yields of methanol radiolysis species are discussed in detail.
\end{abstract}

\section{Introduction}

The preparation of small metal particles at nanometric scale has received increasing attention due to the unique properties of such particles which result from size effects. ${ }^{1-3}$ The radiolytic method is particularly suitable for generating metal clusters in solution. ${ }^{1}$ The radiolytic species, solvated electrons and secondary radicals, exhibit strong reducing properties, such that metal ions are reduced at each encounter. Therefore, the atoms formed through the reduction reactions are distributed homogeneously throughout the solution. Metal atoms then tend to coalesce into oligomers which themselves progressively grow into larger clusters and eventually into precipitates. Moreover, the progressive extent of the reduction is accurately controlled by the dose absorbed and the reduction rate by the dose rate. At quite high dose rate as in pulse radiolysis, an instantaneous distribution of the reducing agent and then of atoms are obtained throughout the solution. For studying stable clusters generally or for specific applications, the coalescence is limited by adding a polymeric molecule acting as a cluster stabilizer. Functional groups with high affinity for the metal ensure the anchoring of the molecule at the cluster surface while the polymeric chain protects the cluster from coalescing at an early stage through electrostatic repulsion or steric hindrance. The final size of the clusters depends on the type of polymer or ligand, the metal/polymer ratio, and the dose rate. ${ }^{3}$ Some changes in the stability and chemical reactivity of the particles are expected if organic solvents are used instead of water. It is already known that silver and gold clusters can be prepared in alcoholic solution by thermal reduction. ${ }^{4,5}$ The rate constant of silver ion reduction by solvated electrons in methanol has been measured by $\gamma$-radiolysis by means of the competition method with the

* Corresponding author. E-mail: mehran.mostafavi@1cp.u-psud.fr.

$\dagger$ Permanent address: EOL from Applied Chemistry Division, Bhabha Atomic Research Centre, Trombay, Mumbai 400085, India. reaction of $\mathrm{N}_{2} \mathrm{O} .^{6}$ Metal clusters have also been chemically prepared in aqueous solutions, and then have been transferred into other solvents of lower polarity. ${ }^{7}$ Their absorption spectra are shifted to the red with a decrease of the solvent polarity, according to the Mie model. The formation dynamics, the size, and the optical properties of radiolytically induced silver clusters have also been recently studied in supercritical ethane/methanol mixtures. ${ }^{8}$

In this work, we present the results concerning the formation of silver clusters in methanol. The size, the optical properties, the growth kinetics, the yields, and the size-dependent reactivity of these clusters with oxygen and with the methyl viologen redox couple are determined. ${ }^{9}$ The silver cations in methanol, similar to silver cations in aqueous solution, could potentially scavenge the total of solvated electrons and of alcohol radicals issued from radiolysis. Thus, we demonstrate that the use of $\mathrm{Ag}^{+}$as a scavenger is helpful in establishing the mechanism of methanol radiolysis. ${ }^{10-13}$

\section{Experimental Section}

All the reagents were pure chemicals: $\mathrm{AgClO}_{4}$ from Aldrich, and methanol, 2-propanol, ethylene glycol, formaldehyde, and methyl viologen chloride $\mathrm{MV}(\mathrm{Cl})_{2}$ from Fluka. The poly(vinyl alcohol) (PVA, hydrolyzed at $80 \%$ with average $M_{\mathrm{w}} 9000-$ $10000 \mathrm{~g} \mathrm{~mol}^{-1}$ ) was from Aldrich. It was used as a stabilizing agent for clusters. For experiments on mixtures of $5 \times 10^{-4} \mathrm{M}$ $\mathrm{AgClO}_{4}$ and $10^{-4} \mathrm{M} \mathrm{MV}(\mathrm{Cl})_{2}$, a supplementary concentration of $10^{-4} \mathrm{M} \mathrm{AgClO}_{4}$ was added in order to eliminate $\mathrm{Cl}^{-}$ions by precipitation of $\mathrm{AgCl}$, then the solution was filtered. The irradiation source was a ${ }^{60} \mathrm{Co} \gamma$-facility of $7000 \mathrm{Ci}$ with a maximum dose rate of $8 \mathrm{kGy} \mathrm{h}^{-1}$. PVA is not soluble in neat methanol. Therefore we used methanol with less than $1 \%$ water. The PVA $\left(2 \times 10^{-1} \mathrm{M}\right)$ and the silver salt $\left(10^{-1} \mathrm{M}\right)$ were first dissolved in water, then diluted with methanol. Due to the extreme sensitivity of clusters in methanol to oxygen, the 


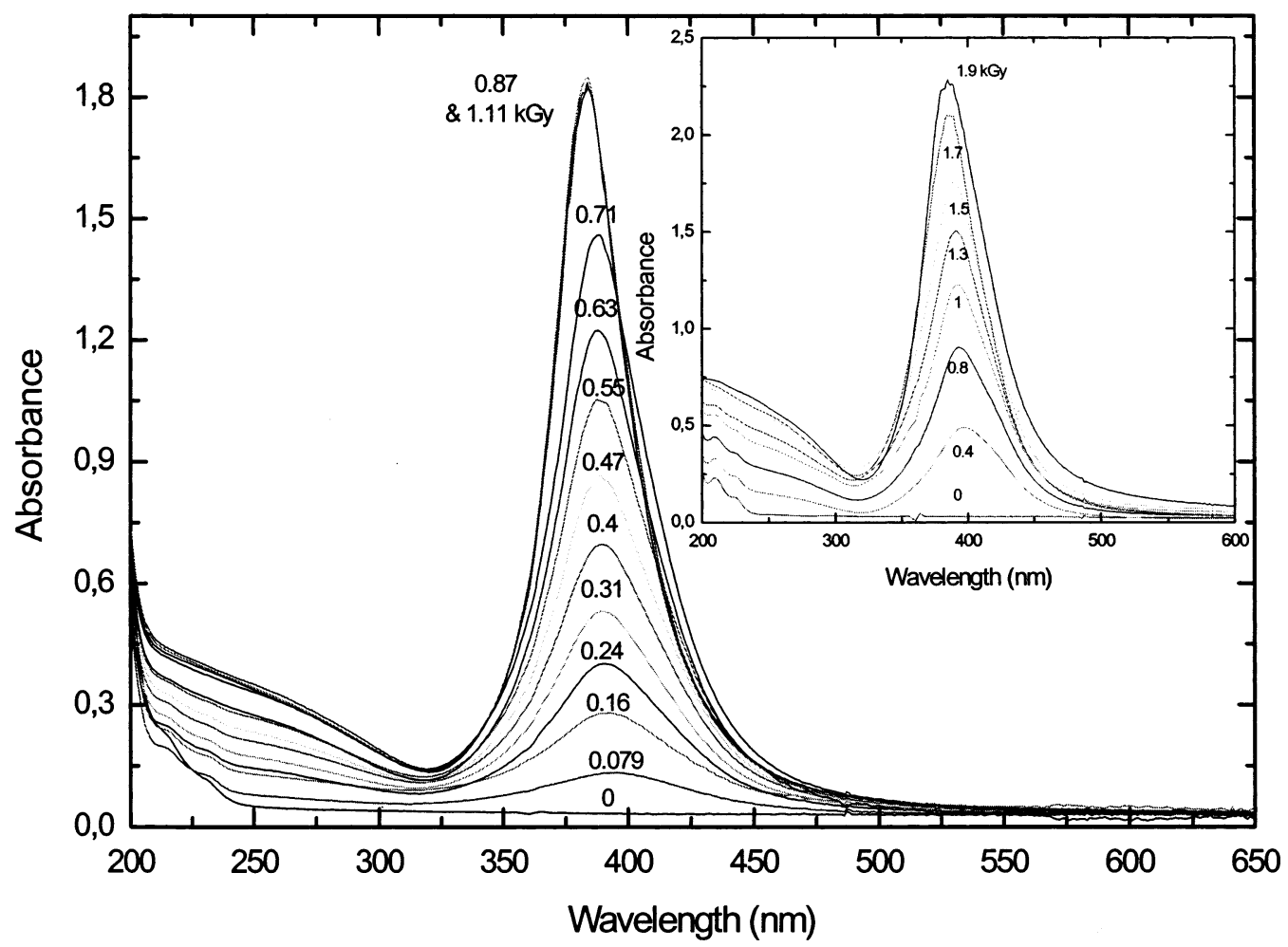

Figure 1. Evolution of absorption spectrum with irradiation dose of deaerated methanolic solutions containing $\mathrm{AgClO}_{4} 5 \times 10^{-4} \mathrm{M}, \mathrm{PVA}_{10} 0^{-3} \mathrm{M}$. $l=2 \mathrm{~mm}$. Inset: Evolution of the absorption spectrum with the $\gamma$-irradiation dose of silver aqueous solutions containing 2-propanol $0.1 \mathrm{M}^{\mathrm{AgClO}} \mathrm{A}_{4}$ $5 \times 10^{-4} \mathrm{M}$, PVA $10^{-3} \mathrm{M} . l=2 \mathrm{~mm}$.

solutions containing silver ions and PVA were deaerated under vacuum before irradiation in a Pyrex irradiation cell connected to an optical cell, to allow the optical spectra to be recorded under vacuum. The optical cell in suprasil is protected by lead shielding during the $\gamma$-irradiation. The dose amount in methanol was determined from the measurement in water by the Fricke dosimeter method and by taking into account the relative electronic density factor. The addition of reactants such as MV$(\mathrm{Cl})_{2}$, formaldehyde, and ethylene glycol was carried out carefully in a deaerated glovebox. Transmission electron microscopy (TEM) images were obtained using a $100 \mathrm{kV}$ transmission electron microscope (JEM 100CX). A drop of cluster sol was dried slowly inside the glovebox flushed by nitrogen, after deposition on the grid.

The details of the pulse radiolysis setup have been reported earlier. ${ }^{14}$ Electron pulses of 3 ns duration were delivered by a Febetron 706 accelerator (600 keV electron energy) to the samples contained in a quartz suprasil cell through a thin entrance window, $0.2 \mathrm{~mm}$ in thickness. The optical path length perpendicular to the electron beam was $1 \mathrm{~cm}$. The dose per pulse was determined from the initial absorbance of the hydrated electron and was around $0.2 \mathrm{kGy}$ (the concentration of $\mathrm{e}^{-}{ }_{\text {aq }}$ at the end of the pulse was around $6 \times 10^{-5} \mathrm{M}$ ). The solution was saturated with very pure $\mathrm{N}_{2}$ and changed after every pulse. Absorbance of the transient species was analyzed by means of a classical xenon (mercury) lamp, monochromator, and photomultiplier setup connected with a transient digitizer. Four to five measurements of transient absorbance for each wavelength were performed in order to correct by averaging for pulse-topulse dose variation.

\section{Results and Discussion}

$\gamma$-Radiolysis Studies of Silver Solutions and Radical Yields in Methanol. Figure 1 shows the evolution of the optical absorption spectra and Figure 2 the variation of the absorbances at $390 \mathrm{~nm}$ as a function of the $\gamma$-irradiation dose. The samples contained $5 \times 10^{-4} \mathrm{M} \mathrm{Ag}^{+}$and $10^{-3} \mathrm{M}$ PVA in methanol under vacuum. At low doses, the plasmon absorption band is quite broad, of low intensity, and displays a maximum at $390 \mathrm{~nm}$. Then, at higher doses, the maximum is slightly shifted to 385 $\mathrm{nm}$, the absorption band is intense, and the bandwidth decreases from 75 to $35 \mathrm{~nm}$ (Figure 3). At around $0.8 \mathrm{kGy}$, the absorbance does not increase any more and the observed plateau corresponds to the complete reduction of metal ions (Figure 2). The average extinction coefficient per atom of silver clusters at $385 \mathrm{~nm}$ is derived from the absorbance value corresponding to the complete reduction of all silver ions and is around $\epsilon\left(\mathrm{Ag}_{n}\right)=$ $1.8 \times 10^{4} \mathrm{M}^{-1} \mathrm{~cm}^{-1}$. The total reduction at $0.8 \mathrm{kGy}$ corresponds to a mean formation yield of atoms close to $G_{\text {red }}=7 \times 10^{-7}$ mol $\mathrm{J}^{-1}$ (Figure 2). However, if the same extinction coefficient is used at any dose, the initial yield is close to $5 \times 10^{-7} \mathrm{~mol}$ $\mathrm{J}^{-1}$ and at the dose of $0.8 \mathrm{kGy}$ is close to $9 \times 10^{-7} \mathrm{~mol} \mathrm{~J}^{-1}$. For the solution containing $10^{-3} \mathrm{M} \mathrm{Ag}^{+}$(Figure 2), the dosedependent absorbance curve is identical to that at $5 \times 10^{-4} \mathrm{M}$ up to $0.8 \mathrm{kGy}$ where the latter solution is not fully reduced. For $10^{-3} \mathrm{M}$ concentration solution, the slope of the curve also increases with the dose. The yield is independent of the actual $\mathrm{Ag}^{+}$concentration and is initially about $G(\mathrm{Ag})=(5 \pm 0.5) \times$ $10^{-7} \mathrm{~mol} \mathrm{~J}^{-1}$ and increases to $G(\mathrm{Ag})=(12 \pm 0.5) \times 10^{-7} \mathrm{~mol}$ $\mathrm{J}^{-1}$ at $1.1 \mathrm{kGy}$.

In the presence of silver cations, the solvated electron is scavenged and $\mathrm{Ag}^{+}$is reduced into $\mathrm{Ag}^{0}$.

$$
\mathrm{e}_{\text {solv }}^{-}+\mathrm{Ag}^{+} \rightarrow \mathrm{Ag}^{0}
$$

The redox potential $E^{\circ}\left(\mathrm{HCHO} /{ }^{\circ} \mathrm{CH}_{2} \mathrm{OH}\right)$ is, at least in water, more positive than that of the couple $\mathrm{Ag}^{+} / \mathrm{Ag}^{0},{ }^{15}$ which would exclude a direct reduction of free $\mathrm{Ag}^{+}$by the radicals ${ }^{\circ} \mathrm{CH}_{2} \mathrm{OH}$. 


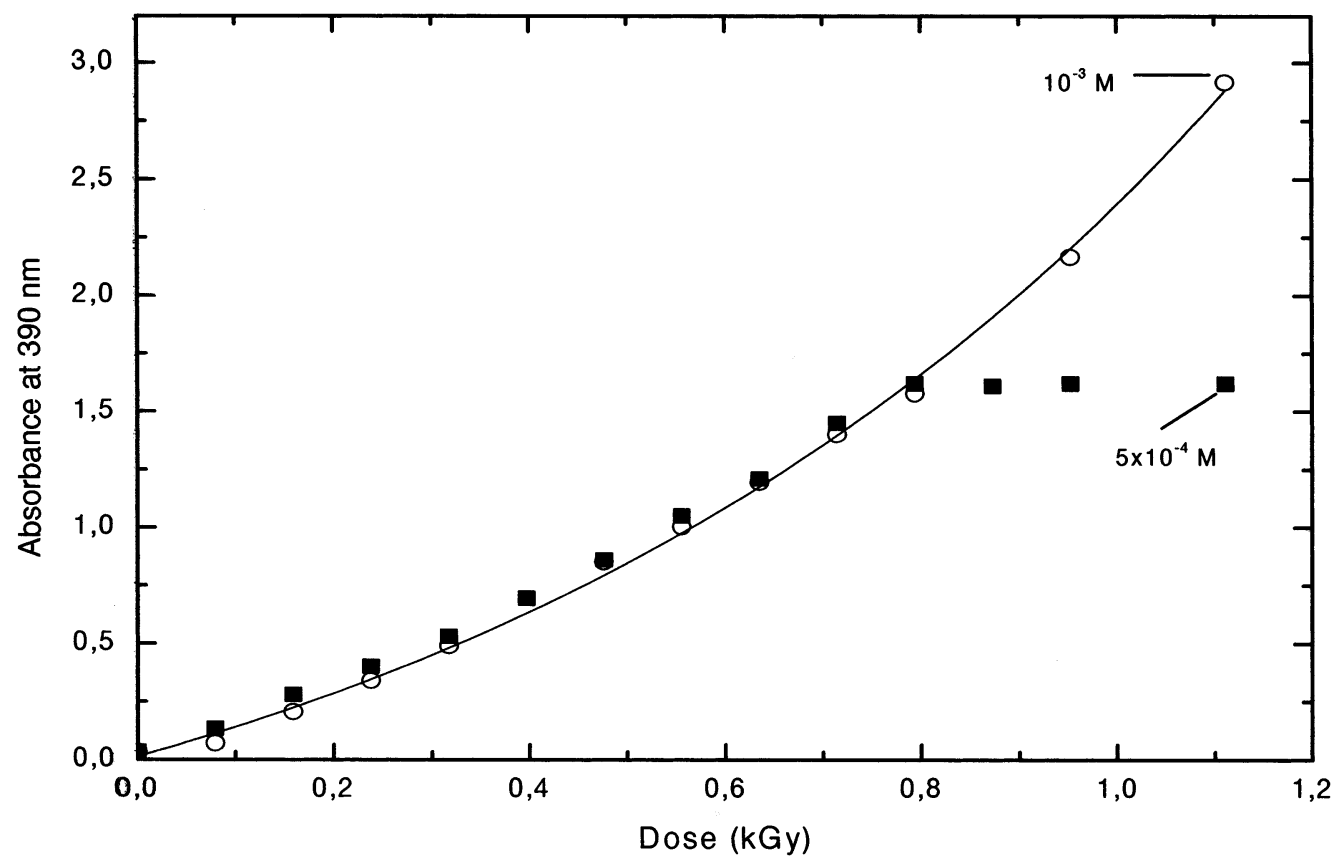

Figure 2. Dose dependence of the absorbance at $390 \mathrm{~nm}$ of methanolic solutions containing $\mathrm{AgClO}_{4} 5 \times 10^{-4} \mathrm{M}^{\text {and }} \mathrm{AgClO}_{4} 10^{-3} \mathrm{M}$. Other conditions as in Figure 1.

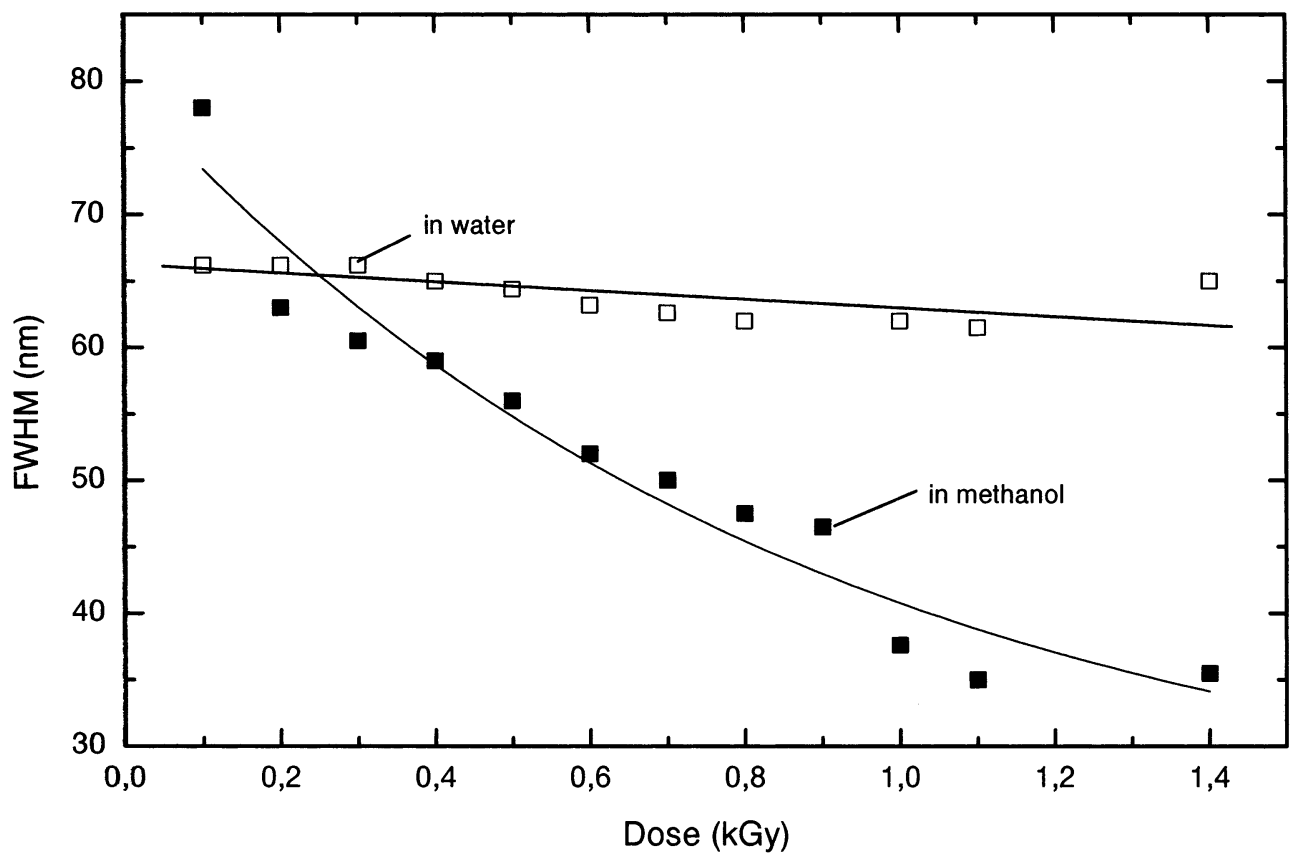

Figure 3. Dose-dependence comparison of silver clusters bandwidth in methanol and water. Conditions as in Figure 1.

However, the reduction of silver cations by radicals ${ }^{\circ} \mathrm{CH}_{2} \mathrm{OH}$ or $\mathrm{CH}_{3} \mathrm{O}^{\bullet}$ adsorbed on clusters whose potential is more positive than that of the atom is possible. Therefore the radicals can contribute to the reduction of adsorbed silver cations after cluster accumulation in the solution.

$$
{ }^{\bullet} \mathrm{CH}_{2} \mathrm{OH}+\mathrm{Ag}_{n}{ }^{+} \rightarrow \mathrm{HCHO}+\mathrm{Ag}_{n}+\mathrm{H}^{+}
$$

Note that the concentration $\left[\mathrm{Ag}_{n}{ }^{+}\right]$of charged nanoclusters is $5 \times 10^{-8}-10^{-7} \mathrm{M}$ only, which explains why the radical scavenging (reaction 2), which is in competition with the radical dimerization or disproportionation, is not complete at low dose. Reaction 2 is favored at higher doses where $\mathrm{Ag}_{n}{ }^{+}$has a higher concentration.
It was also observed that the concentration of silver clusters (in the $5 \times 10^{-4} \mathrm{M} \mathrm{Ag}^{+}$solution partially reduced by $\gamma$-irradiation) increases very slowly after the end of irradiation. In that case, the radiolytic $\mathrm{H}_{2}$ is present but at an extremely low pressure. We then considered that the increase of the yield $G(\mathrm{Ag})$ with the dose could be due to a thermal reaction. Because ethylene glycol and formaldehyde are among the final products of pure methanol radiolysis, ${ }^{11}$ we have studied therefore the possible reduction of $\mathrm{Ag}^{+}$by these molecules in the presence of silver clusters. For this purpose, samples of $5 \times 10^{-4} \mathrm{M}$ $\mathrm{Ag}^{+}$solution were irradiated only with $0.25 \mathrm{kGy}$ (resulting in $28 \%$ reduction) and then an amount of formaldehyde or ethylene glycol $\left(10^{-3} \mathrm{M}\right)$ was added under inert atmosphere (therefore, after withdrawing radiolytic molecular hydrogen). In both cases 

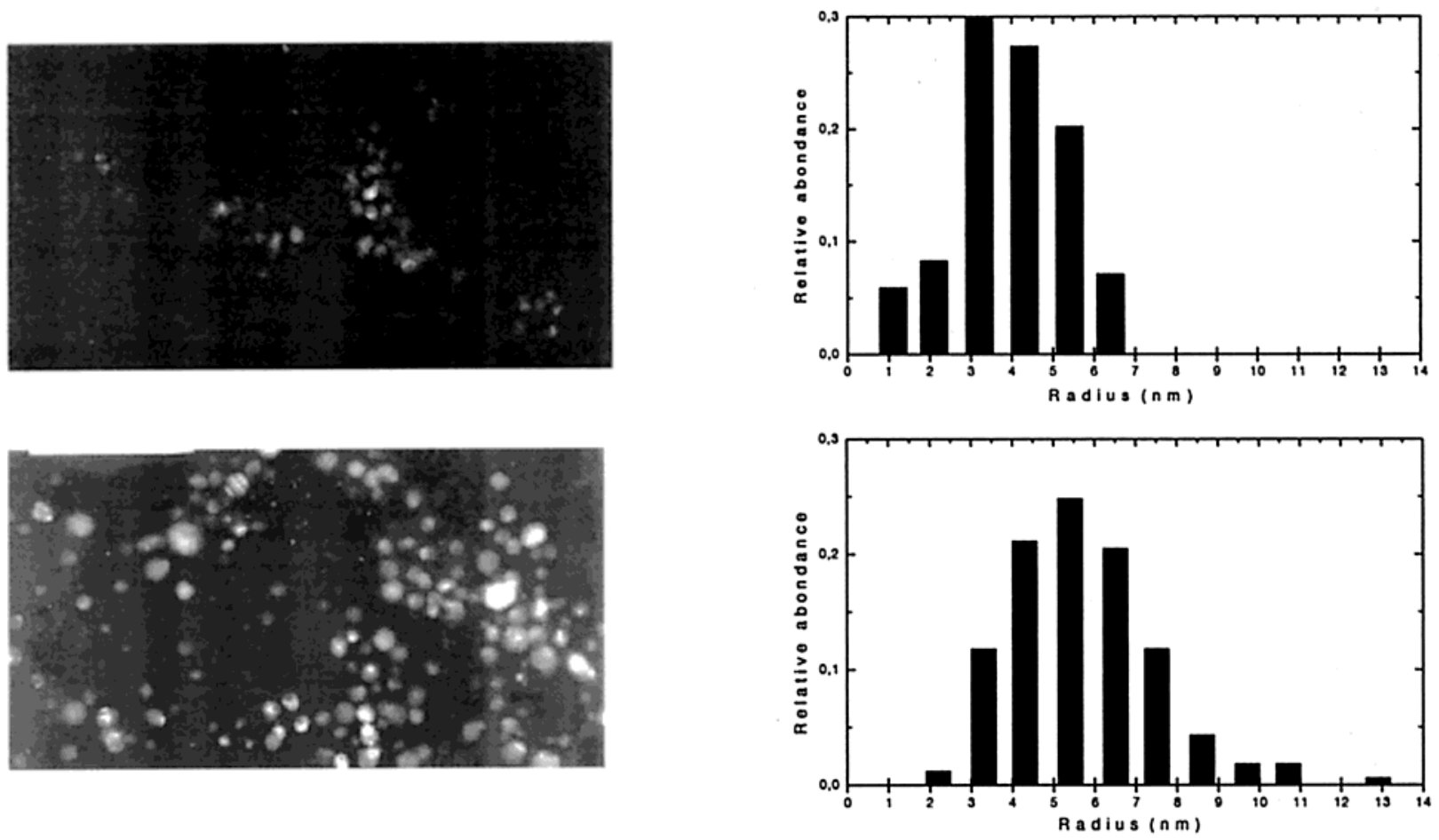

Figure 4. Microscopy images by TEM and size-distribution of irradiated samples of silver solutions in methanol up to complete reduction. Dose $=0.8 \mathrm{kGy}$. Top: Same conditions as in Figure 1, Bottom: After addition of $10^{-3} \mathrm{M} . \mathrm{MV}^{2+}$.

the reduction of $\mathrm{Ag}^{+}$at the surface of clusters was extremely slow and lasted for a few days. The post-irradiation effect must be assigned to a slow thermal reaction with the radiolytic formaldehyde or/and ethylene glycol. After 1 day, the supplementary cluster formation corresponds already to a reduction equivalent yield of $3.5 \times 10^{-7} \mathrm{~mol} \mathrm{~J}^{-1}$ or $G\left(\left(\mathrm{CH}_{2} \mathrm{OH}\right)_{2}+\right.$ $\mathrm{HCHO})=1.8 \times 10^{-7} \mathrm{~mol} \mathrm{~J}^{-1}$. However, this slow thermal process is negligible when the spectrum is recorded just after the irradiation. For example the further reduction of $\mathrm{Ag}_{n}{ }^{+}$by $\mathrm{HCHO}$ produced in reaction 2 is very slow and not probable immediately after the irradiation.

At complete reduction of $\mathrm{Ag}^{+}$, no change is detected in the absorption spectrum even after $30 \mathrm{~h}$ and the clusters are stable under vacuum or inert atmosphere. The size of the particles at the end of irradiation, obtained by TEM from a drop dried in a glovebox flushed by $\mathrm{N}_{2}$, is around $3.5 \mathrm{~nm}$ (nuclearity $n=10^{4}$ atoms per cluster) (Figure 4 , top).

Surprisingly, the clusters are dramatically oxidized as soon as the solutions are in contact with air and the plasmon band around $385 \mathrm{~nm}$ is notably bleached and the maximum is shifted to $410 \mathrm{~nm}$ (Figure 5). Actually, owing to the strong reducing properties of a solvent such as methanol, we had expected instead an enhancement of the stability of the silver clusters toward oxidation. When an amount corresponding to a final concentration of $10^{-3} \mathrm{M}$ of $\mathrm{MV}^{2+}$ is added to the solution containing silver clusters under vacuum, a transient blue color assigned to $\mathrm{MV}^{+}$is observed and lasts for one second before disappearing. The absorption spectrum of the silver clusters obtained when the blue color has disappeared differs markedly from that recorded before the addition of $\mathrm{MV}^{2+}$ (Figure 5). The intense plasmon band at $385 \mathrm{~nm}$ is replaced by a new, lessintense but broader absorption plasmon band around $410 \mathrm{~nm}$. Moreover, after the reaction with $\mathrm{MV}^{2+}$, the cluster size is much larger: $6.5 \mathrm{~nm}\left(n=6.3 \times 10^{4}\right.$ atoms per cluster) (Figure 4 bottom) and the clusters are stable in air.

For an accurate comparison between solvents, the spectra are recorded under identical conditions of PVA concentration $\left(10^{-3}\right.$
M) and dose rate in aqueous solution. The aqueous solution contained 2-propanol at $0.1 \mathrm{M}$ to scavenge $\mathrm{H}^{\bullet}$ and $\mathrm{OH}^{\bullet}$ radicals and replace them by the reducing radical $\left(\mathrm{CH}_{3}\right)_{2} \mathrm{C}^{\bullet} \mathrm{OH}$. The wellknown plasmon absorption band ${ }^{16}$ of the silver clusters, stabilized by the polymer, with a maximum around 400-410 $\mathrm{nm}$ (extinction coefficient per atom $\epsilon=9800 \mathrm{M}^{-1} \mathrm{~cm}^{-1}$ ) is developed at increasing irradiation doses (Figure 1, inset). The yield of the cluster formation is close to $G_{\text {red }}=6 \times 10^{-7} \mathrm{~mol}$ $\mathrm{J}^{-1}$ as reported in the literature. ${ }^{16}$ In water, the clusters are stable in the presence of air for several days without any significant change of the absorption band. The width of the plasmon band of the silver clusters obtained at different doses is almost constant $(65 \mathrm{~nm})$ (Figure 3$)$. The size of the silver particle obtained at the end of irradiation under vacuum with a dose of $0.8 \mathrm{kGy}$ is much larger in water (around $15 \mathrm{~nm}$ ) than in methanol $(3.5 \mathrm{~nm})$.

The analysis by TEM (Figure 4) and the spectra (Figure 1) show clearly that the final size of clusters prepared in methanolic solution are quite small despite the low concentration of PVA and much smaller than in aqueous solution under similar conditions. Note also that the silver clusters spontaneously formed by chemical reduction in alkaline 2-propanol possess an absorption band around $390 \mathrm{~nm}$ with $\epsilon_{390 \mathrm{~nm}}=7600 \mathrm{M}^{-1}$ $\mathrm{cm}^{-1}$ and display a diameter of a few nanometers. The plasmon band maximum of silver clusters in methanol lies at $385 \mathrm{~nm}$, instead of close to $400 \mathrm{~nm}$ in water. The difference between the positions of the maxima is thus less important than with other solvents as found for gold clusters. ${ }^{7}$ According to the Mie model, the maximum wavelength for a given metal cluster depends on the refractive index, which is almost the same in methanol (1.331) and in water (1.333), and also on the cluster size, which is much smaller in methanol. For the same reason, the extinction coefficient per atom at the absorption maximum is in methanol $\epsilon_{385 \mathrm{~nm}}=1.8 \times 10^{4} \mathrm{M}^{-1} \mathrm{~cm}^{-1}$, that is much higher than that found under strictly the same conditions in water $\epsilon_{410 \mathrm{~nm}}$ $=9.8 \times 10^{3} \mathrm{M}^{-1} \mathrm{~cm}^{-1}$, and the band is sharper (35 instead of $65 \mathrm{~nm})$. 


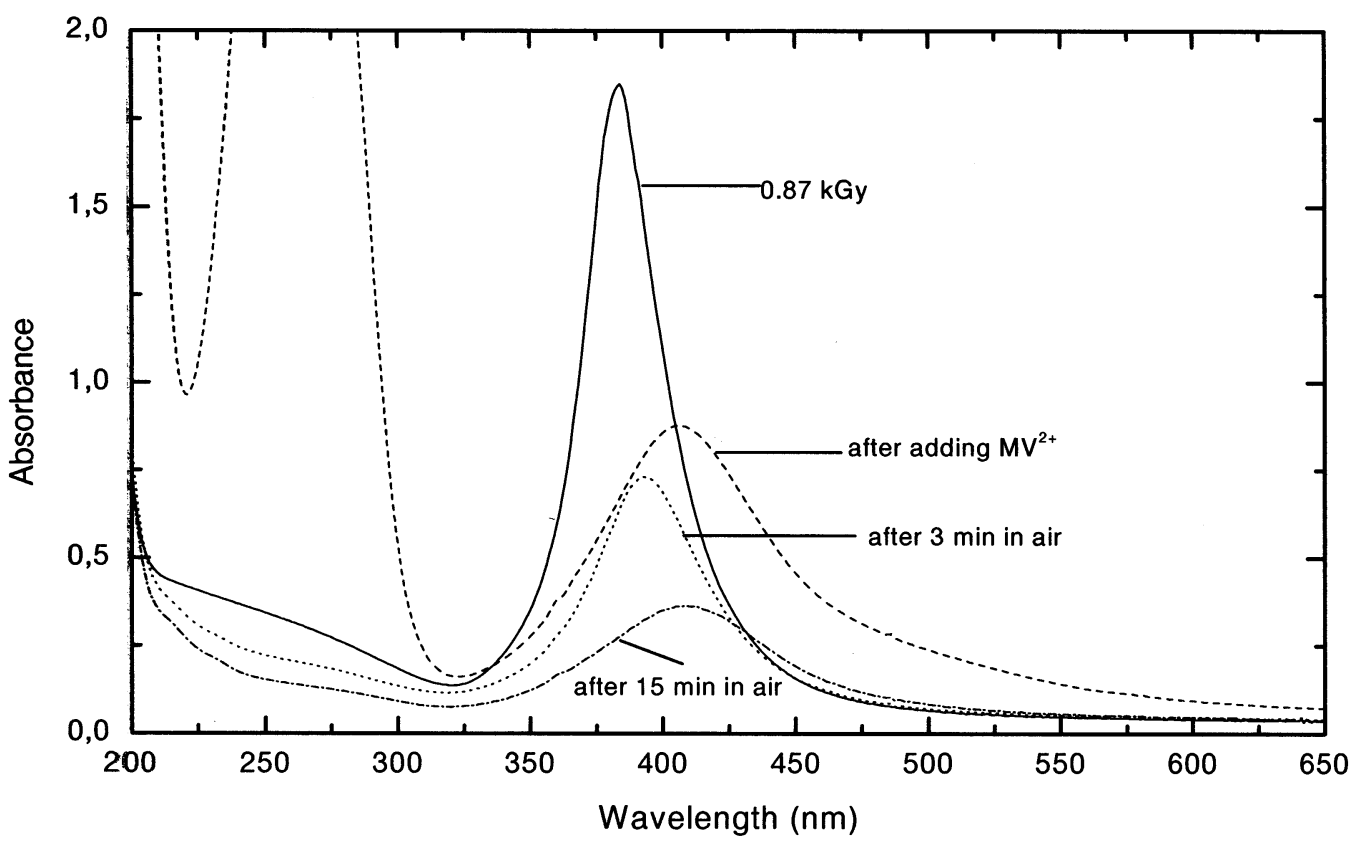

Figure 5. Absorption spectra of silver clusters: At the end of $\gamma$-radiolytic reduction $(0.8 \mathrm{kGy}$, other conditions as in Figure 1$)$ and after 3 and 15 min in contact with air, also after addition of $\mathrm{MV}^{2+} 10^{-3} \mathrm{M}$.

Another important behavior difference with aqueous solutions is that a fraction of silver clusters is readily oxidized in aerated methanolic solution (whereas they are stable when in contact with air). The oxidation by air of small silver particles in basic alcoholic solution has been also suggested. ${ }^{5}$ This result implies that the redox potential of at least part of the clusters, which are probably complexed in methanol solution, is lower than that of the oxygen couple $E^{\circ} \mathrm{O}_{2} / \mathrm{O}_{2}{ }^{-}=-0.16 \mathrm{~V}_{\mathrm{NHE}}$ (in water).

After the primary $\gamma$-ionization and excitation of methanol (reaction 3), the overall reaction of methanol radiolysis as generally accepted in the literature ${ }^{10-13,17-21}$ is as follows:

$$
\begin{aligned}
& \mathrm{CH}_{3} \mathrm{OH} \rightsquigarrow \mathrm{CH}_{3} \mathrm{OH}^{+\bullet}, \mathrm{e}^{-}, \mathrm{CH}_{3} \mathrm{OH}^{*} \rightarrow \mathrm{e}_{\text {solv }}^{-} \text {, } \\
& \mathrm{CH}_{3} \mathrm{OH}_{2}{ }^{+}, \mathrm{H}^{\bullet}, \mathrm{CH}_{3} \mathrm{O}^{\bullet},{ }^{\circ} \mathrm{CH}_{2} \mathrm{OH},{ }^{\circ} \mathrm{CH}_{3}, \mathrm{H}_{2}, \mathrm{CH}_{4} \text {, } \\
& \left(\mathrm{CH}_{2} \mathrm{OH}\right)_{2}, \mathrm{HCHO}, \mathrm{CO}
\end{aligned}
$$

Eventually, the products in neat methanol radiolysis are known to be yielded with the $G$-values (in $10^{-7} \mathrm{~mol} \mathrm{~J}^{-1}$ ): ${ }^{11}$

$$
\begin{aligned}
& (9.4 \pm 0.6) \mathrm{CH}_{3} \mathrm{OH} m(5.8 \pm 0.1) \mathrm{H}_{2}+ \\
& (3.52 \pm 0.2)\left(\mathrm{CH}_{2} \mathrm{OH}\right)_{2}+(1.85 \pm 0.1) \mathrm{HCHO}+ \\
& (0.43 \pm 0.03) \mathrm{CH}_{4}+(0.13 \pm 0.03) \mathrm{CO}
\end{aligned}
$$

The yield value of each species depends indeed on the time considered and on the scavenging factor of the solute. From picosecond pulse radiolysis experiments at high concentration of electron scavengers such as $\mathrm{Cd}^{2+}$ or biphenyl, it has been found that the initial ionization yield in methanol before electron solvation is $G^{0}$ (ion) $=(4 \pm 0.4) \times 10^{-7} \mathrm{~mol} \mathrm{~J}^{-1} .^{18}$ The solvated electron yield corresponding to the free ion yield at $10^{-7}-$ $10^{-6} \mathrm{~s}$ is $G\left(\mathrm{e}^{-}\right.$solv $)=2 \times 10^{-7} \mathrm{~mol} \mathrm{\textrm {J } ^ { - 1 }} .^{20}$ The other main radiolytic species with reducing properties is the ${ }^{\circ} \mathrm{CH}_{2} \mathrm{OH}$ radical which is arising from isomerization of $\mathrm{CH}_{3} \mathrm{O}{ }^{*},{ }^{10}$ and possibly also from dissociation of excited methanol molecules formed in reaction 3 or from reactions of the primary cation $\mathrm{CH}_{3} \mathrm{OH}^{+}$. and $\mathrm{H}^{\bullet}$ atoms with methanol. It is clear that primary cations $\mathrm{CH}_{3} \mathrm{OH}^{+}, \mathrm{H}^{\bullet}$ atoms, ${ }^{\cdot 5} \mathrm{CH}_{3}, \mathrm{OH}^{\bullet}$, and $\mathrm{CH}_{3} \mathrm{O}^{\bullet}$ radicals disappear rapidly due to reactions with the solvent, and will not react with solutes but concentrated.

Most of the literature data on the methanol radiolysis were obtained with specific electron scavengers such as $\mathrm{N}_{2} \mathrm{O},{ }^{6} \mathrm{SF}_{6},{ }^{17}$ $\mathrm{CH}_{3} \mathrm{Br},{ }^{17}$ biphenyl, ${ }^{18} \mathrm{Cd}^{2+},{ }^{18}$ and $\mathrm{Ag}^{+6}$ and concern the electron yield. The radiolytic products resulting from oxidized radical and electron scavenging by triethylsilane $\mathrm{R}_{3} \mathrm{SiH}$ methanolic solutions were carefully analyzed and a mechanism for their formation proposed. ${ }^{23}$ Because of the multiplicity of products, even in pure methanol, and of the variable scavenging action of solutes, the mechanism is complex and still under debate. Nevertheless, the analysis of the literature and of the present data on $\gamma$-radiolysis of silver solutions allows us to establish the quantitative branchings of the scheme. A scheme of the general mechanism of the methanol radiolysis with the different branchings and yields is tentatively presented in Figure 6.

The initial electron yield found at the highest electron scavenger concentrations or at picosecond range is $G_{\mathrm{e}^{-}}^{0}=G_{\text {ion }}^{0}$ $=(4 \pm 0.4) \times 10^{-7} \mathrm{~mol} \mathrm{~J}{ }^{-1} \cdot{ }^{19}$ The molecular hydrogen $\left(G\left(\mathrm{H}_{2}\right)_{\text {neat }}=5.8 \times 10^{-7} \mathrm{~mol} \mathrm{~J}^{-1}\right)$ originates directly from excited molecule dissociation and indirectly from scavenging of $\mathrm{H}$-atoms by methanol:

$$
G\left(\mathrm{H}_{2}\right)_{\text {neat }}=G_{\mathrm{H}_{2}}^{0}+G_{\mathrm{e}^{-}{ }_{\text {solv }}}^{0}+G_{\mathrm{H}^{\cdot}}^{0}=5.8 \times 10^{-7} \mathrm{~mol} \mathrm{~J}^{-1}
$$

The initial yield $G^{0} \cdot{ }^{\circ} \mathrm{CH}_{3}=G^{0}{ }^{\circ} \mathrm{OH}$ is assumed to be equal to $G\left(\mathrm{CH}_{4}\right)_{\text {neat }}=(0.43 \pm 0.03) \times 10^{-7} \mathrm{~mol} \mathrm{~J}^{-1}$. The product $\mathrm{CO}$ is supposed to arise with $G(\mathrm{CO})=(0.13 \pm 0.03) \times 10^{-7} \mathrm{~mol}$ $\mathrm{J}^{-1}$ from a further oxidation by 2 radicals of the molecular products $\mathrm{HCHO}$ or $\left(\mathrm{CH}_{2} \mathrm{OH}\right)_{2}$ (with a yield equal to $(0.52 \pm$ $0.1) \times 10^{-7} \mathrm{~mol} \mathrm{~J}^{-1}$ ).

The $\gamma$-reduction yield of silver ions is at low dose $G(\mathrm{Ag})=$ $5 \times 10^{-7} \mathrm{~mol} \mathrm{~J}^{-1}$ and it increases at higher doses when some clusters are already present up to $9 \times 10^{-7} \mathrm{~mol} \mathrm{~J}^{-1}$ (at initial $\left[\mathrm{Ag}^{+}\right]=5 \times 10^{-4} \mathrm{M}$ ) and up to $12 \times 10^{-7} \mathrm{~mol} \mathrm{~J}{ }^{-1}$ (at initial $\left[\mathrm{Ag}^{+}\right]=10^{-3} \mathrm{M}$ ) (Figure 2). This corresponds partly to the free electron yield which is $G^{0} \mathrm{e}^{-}{ }_{\text {solv }}=2.0 \times 10^{-7} \mathrm{~mol} \mathrm{~J}^{-1}{ }^{10}$ for a scavenging factor $k_{1} \times\left[\mathrm{Ag}^{+}\right]=(1.3$ to 2.6$) \times 10^{7} \mathrm{~s}^{-1}$ 


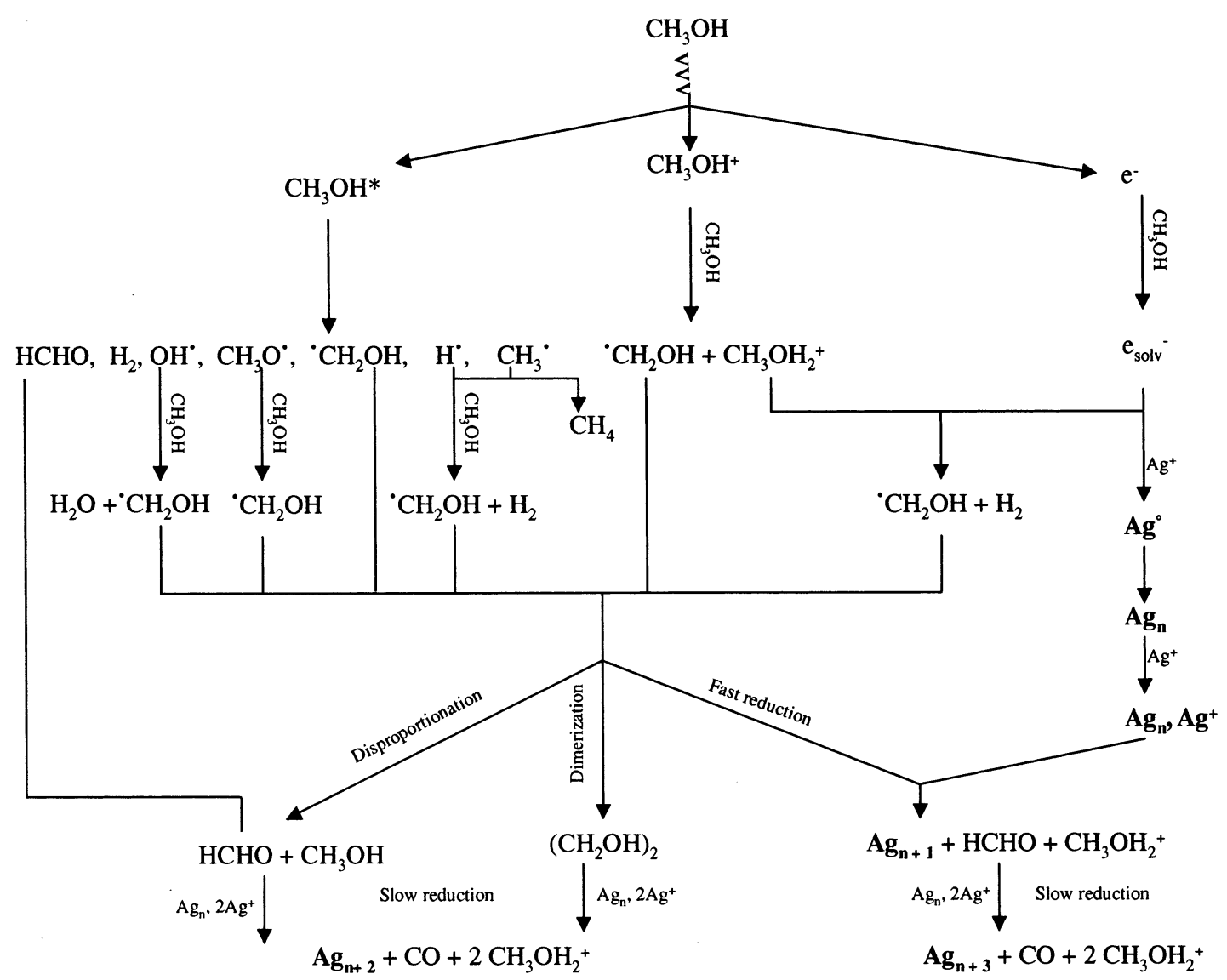

Figure 6. Scheme of the mechanism of $\gamma$-radiolysis of silver-methanol solutions. The formation of $\mathrm{CO}$ (not written, $G(\mathrm{CO})=0.13 \times 10^{-7} \mathrm{~mol}$ $\left.\mathrm{J}^{-1}\right)$ is supposed to arise from the secondary attack of $\mathrm{HCHO}$ and $\left(\mathrm{CH}_{2} \mathrm{OH}\right)_{2}$ by 2 radicals. For $\left[\mathrm{Ag}_{n}{ }^{+}\right] \approx 10^{-7} \mathrm{M}$, the dimerization and disproportionation of the radicals are negligible compared to their fast reduction of $\mathrm{Ag}_{n}{ }^{+}$, but at lower $\mathrm{Ag}_{n}{ }^{+}$concentration they occur. $\mathrm{The}^{-}$dissociation of $\mathrm{CH}_{3} \mathrm{OH}^{*}$ into $\mathrm{HCHO}+\mathrm{H}_{2}$ is a minor process (see text).

(reaction 1). The rest does not result from a reaction with ethylene glycol or formaldehyde, which would be too slow. Therefore, it must be assigned to a contribution to the yield, increasing from 3 up to $10 \times 10^{-7} \mathrm{~mol} \mathrm{~J}^{-1}$, from the radicals ${ }^{\circ} \mathrm{CH}_{2} \mathrm{OH}$ which reduce silver cations adsorbed on clusters acting as catalysts (reaction 2).

The scheme of Figure 6 shows that $\mathrm{e}^{-}$solv are reducing either directly $\mathrm{Ag}^{+}$or indirectly $\mathrm{Ag}_{n}{ }^{+}$after the production of a radical ${ }^{-} \mathrm{CH}_{2} \mathrm{OH}$. The charged silver clusters $\mathrm{Ag}_{n}{ }^{+}$are also reduced by radicals formed by the ion-molecule reaction of positive primary cations, thereby doubling $G^{0}{ }^{-}{ }_{\text {solv }}$, and by radicals issued from excited molecules with a yield double of $\mathrm{G}^{0} \mathrm{H}^{\cdot}+\mathrm{G}^{0}{ }^{\circ} \mathrm{CH}_{3}$ :

$$
\begin{aligned}
& G\left(n \mathrm{Ag}_{n}\right)=12 \times 10^{-7} \mathrm{~mol} \mathrm{~J}^{-1}= \\
& 2 G_{\mathrm{e}^{-}{ }_{\text {solv }}}^{0}+G_{\mathrm{H}^{\bullet}}^{0}+G_{\mathrm{CH}_{3} \mathrm{O} \cdot}^{0}+G^{0}{ }_{{ }_{\mathrm{CH}_{2} \mathrm{OH}}}+G^{0}{ }_{{ }_{\mathrm{CH}_{3}}}+G^{0}{ }_{\mathrm{OH} \bullet}= \\
& 2\left(G_{\mathrm{e}^{-}{ }_{\text {solv }}}^{0}+G^{0}{ }_{\mathrm{H}^{\bullet}}+G^{0}{ }_{{ }_{\mathrm{CH}}}\right)
\end{aligned}
$$

This value is indeed close to the total yield of the radicals in neat methanol which produce eventually formaldehyde, glycol, and $\mathrm{CO}$. We remark that the part of solvated electrons that is not scavenged by $\mathrm{Ag}^{+}$also contributes after recombination with $\mathrm{CH}_{3} \mathrm{OH}_{2}{ }^{+}$to the formation of the radical ${ }^{\circ} \mathrm{CH}_{2} \mathrm{OH}$ which is scavengeable by charged clusters. Thus, the total reduction yield into silver atoms depends more on the cluster than on the ion concentration (at low dose, the curves at different concentrations of $\mathrm{Ag}^{+}$are identical in Figure 2).

By comparing eqs 5 and 6 , the $G$-values of some species corresponding to branchings in Figure 6 are obtained:

$$
\begin{aligned}
& G^{0}{ }_{{ }_{\mathrm{CH}_{3}}}-G_{\mathrm{H}_{2}}^{0}=0.2 \times 10^{-7} \mathrm{~mol} \mathrm{~J}{ }^{-1} \text { or } G_{\mathrm{H}_{2}}^{0}=G_{\mathrm{HCHO}}^{0}= \\
& 0.23 \times 10^{-7} \mathrm{~mol} \mathrm{~J}^{-1} \\
& G_{\mathrm{H}^{\bullet}}^{0}=G_{\mathrm{CH}_{3} \mathrm{O} \cdot}^{0}+G^{0}{ }_{\mathrm{CH}_{2} \mathrm{OH}}=1.57 \times 10^{-7} \mathrm{~mol} \mathrm{~J}^{-1} \\
& G_{\text {exc }}^{0}=G_{\mathrm{H}^{\cdot}}^{0}+G_{\mathrm{H}_{2}}^{0}+G_{\mathrm{CH}_{3}}^{0}= \\
& (2.23 \pm 0.5) \times 10^{-7} \mathrm{~mol} \mathrm{~J}^{-1}
\end{aligned}
$$

It is noteworthy that $G^{0} \mathrm{H}_{2}$ and $G^{0}{ }_{\mathrm{HCHO}}$ arising from excitation are very low (almost in the range of experimental uncertainties affecting the measured yields). It seems therefore that the origin of the "unscavengeable" molecular hydrogen in concentrated scavenger solutions ${ }^{11}$ with an upper limit of $1.75 \times 10^{-7} \mathrm{~mol}$ $\mathrm{J}^{-1}$ is not primary hydrogen, but mostly secondary hydrogen early formed by reactions of unscavenged $\mathrm{H}$-atom and $\mathrm{e}^{-}$solv.

Pulse Radiolysis Studies. The decay of solvated electrons at $620 \mathrm{~nm}\left(\lambda_{\max }=630 \mathrm{~nm}\right)^{22}$ was observed as much faster in the presence of $\mathrm{AgClO}_{4}$ (without polymer) (Figure 7, inset) than in neat methanol. The bimolecular rate constant for reaction 1 between $\mathrm{e}^{-}$solv and $\mathrm{Ag}^{+}$was determined from the slope of the linear concentration dependence of the observed pseudo-firstorder rate constant of $\mathrm{e}^{-}$solv in the range $\left[\mathrm{Ag}^{+}\right]=(0.5-5) \times$ $10^{-4} \mathrm{M}$ and was found to be $k_{1}=(2.6 \pm 0.6) \times 10^{10} \mathrm{M}^{-1} \mathrm{~s}^{-1}$. In other pulse radiolysis measurements in the range $(0.02$ to $1.9) \times 10^{-3} \mathrm{M}$, the slope gives $3.5 \times 10^{10} \mathrm{M}^{-1} \mathrm{~s}^{-1}$. Our value is also in agreement with the rate constant $k_{1}=4.7 \times 10^{9} \mathrm{M}^{-1}$ $\mathrm{s}^{-1}$ at $0{ }^{\circ} \mathrm{C}$ found by competition with the $\mathrm{N}_{2} \mathrm{O}$ reaction. ${ }^{6}$

The evolution with time $(50-700 \mathrm{~ns})$ of the transient absorption spectra obtained by pulse radiolysis in $5 \times 10^{-4} \mathrm{M}$ 


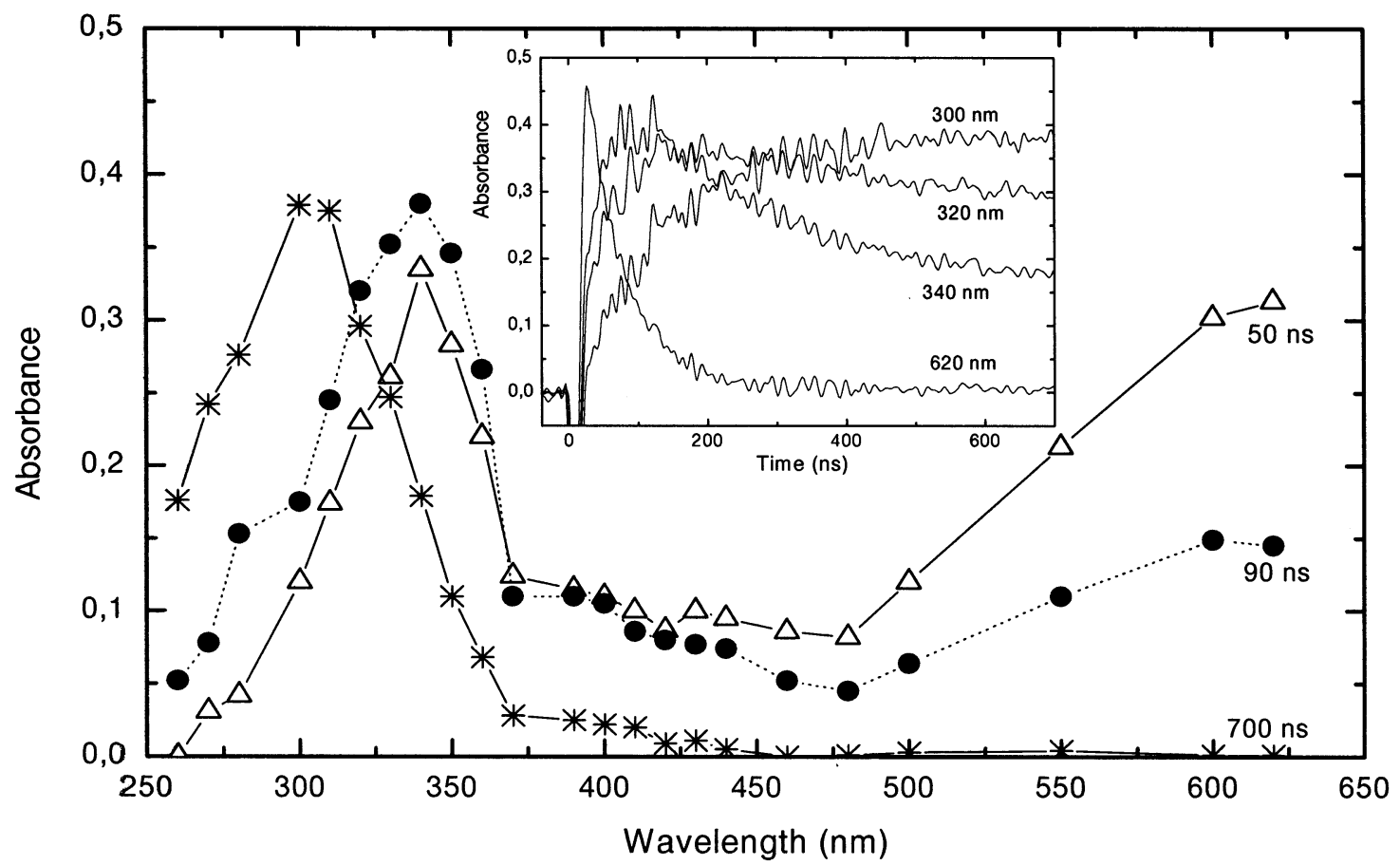

Figure 7. Transient spectra of deaerated methanolic solution of $\mathrm{AgClO}_{4} 5 \times 10^{-4} \mathrm{M}$ up to $700 \mathrm{~ns}$. Inset: Kinetics signals at 300 , 320, 340, and $620 \mathrm{~nm}$.

$\mathrm{AgClO}_{4}$ methanolic solution with $\mathrm{N}_{2}$ atmosphere is shown in Figure 7. At this initial concentration almost all solvated electrons are scavenged by $\mathrm{Ag}^{+}$(reaction 1). Within $90 \mathrm{~ns}$ after the electron pulse, an absorption band with a maximum at around $(340 \pm 5) \mathrm{nm}$ is increasing simultaneously with the decay of the solvated electron band at $620 \mathrm{~nm}$. The $340 \mathrm{~nm}$ band is thus assigned to the silver atom $\mathrm{Ag}^{0}$.

It seems that no species other than solvated electrons are participating to the pulse radiolysis reduction of silver cations. In particular, the radicals ${ }^{\circ} \mathrm{CH}_{2} \mathrm{OH}$ dimerize or disproportionate more efficiently than in $\gamma$-radiolysis due to their higher concentration and to the high rate constant $k=2.8 \times 10^{9} \mathrm{M}^{-1}$ $\mathrm{s}^{-1} .{ }^{23}$ Thus they might have disappeared before larger oligomers are formed and before silver cations could adsorb on them.

The extinction coefficient of $\mathrm{e}^{-}$solv at the maximum is $\epsilon\left(\mathrm{e}_{\text {solv }}{ }^{-}\right)$ $=1.02 \times 10^{4} \mathrm{M}^{-1} \mathrm{~cm}^{-1} \cdot{ }^{24}$ From the increase of the absorbance at $340 \mathrm{~nm}$ during the first $50 \mathrm{~ns}$ after the pulse compared to the decrease of $\mathrm{e}^{-}$solv at $620 \mathrm{~nm}$, we derive $\epsilon\left(\mathrm{Ag}^{0}\right)=9.6 \times 10^{3}$ $\mathrm{M}^{-1} \mathrm{~cm}^{-1}$.

Then the solvated electrons continue to decay up to their complete disappearance at $300 \mathrm{~ns}$. But at $340 \mathrm{~nm}$, the $\mathrm{Ag}^{0}$ absorbance reaches its highest value at $90 \mathrm{~ns}$ (Figure 7, inset) and then starts decaying, while an absorbance increase is recorded at $300 \mathrm{~nm}$ up to a maximum reached at $700 \mathrm{~ns}$. An isosbestic point is observed close to $325 \mathrm{~nm}$ between 90 and $700 \mathrm{~ns}$. The time profiles obtained at different wavelengths in the range 50-700 ns (Figure 7, inset) do not correspond indeed to the formation of only one species but at least of two. By analogy with water solutions, ${ }^{16}$ the spectrum with a maximum at $(305 \pm 5) \mathrm{nm}$ is assigned to the charged dimer $\mathrm{Ag}_{2}{ }^{+}$produced from the further reaction of an atom with excess silver cations, and possibly too to the doubly charged $\mathrm{Ag}_{3}{ }^{2+} .25$

$$
\begin{gathered}
\mathrm{Ag}^{0}+\mathrm{Ag}^{+} \rightarrow \mathrm{Ag}_{2}{ }^{+} \\
\mathrm{Ag}_{2}{ }^{+}+\mathrm{Ag}^{+} \rightarrow \mathrm{Ag}_{3}{ }^{2+}
\end{gathered}
$$

From the absorbance intensities of $\mathrm{Ag}^{0}$ at $340 \mathrm{~nm}$ after 90 ns and of $\mathrm{Ag}_{2}{ }^{+}$at $305 \mathrm{~nm}$ after $700 \mathrm{~ns}$, we conclude that the extinction coefficient of $\mathrm{Ag}_{2}{ }^{+}$is close to that of $\mathrm{Ag}^{0}$, that is $\epsilon\left(\mathrm{Ag}_{2}{ }^{+}\right)_{305 \mathrm{~nm}}=9.5 \times 10^{3} \mathrm{M}^{-1} \mathrm{~cm}^{-1}$.

At a longer time scale (Figure 8), the $\mathrm{Ag}_{2}{ }^{+}$band at $305 \mathrm{~nm}$ also decreases for more than $20 \mu \mathrm{s}$ and is replaced by another band with a maximum around $270 \mathrm{~nm}$, which we assign to oligomers $\mathrm{Ag}_{4}{ }^{2+}$ by analogy with the data in water. ${ }^{25}$

$$
\mathrm{Ag}_{2}^{+}+\mathrm{Ag}_{2}^{+} \rightarrow \mathrm{Ag}_{4}^{2+}
$$

The absorbance at $270 \mathrm{~nm}$ increases slowly for $30 \mathrm{~ms}$ (Figures 9 and 10). Meanwhile, bands of low intensity are growing in the range $300-450 \mathrm{~nm}$ that we assign to oligomers of higher nuclearity. In water, oligomers larger than $\mathrm{Ag}_{4}{ }^{2+}$ have been found at 300,325 , and $355 \mathrm{~nm}^{25}$

The last step corresponds to a very slow decay of the 270 $\mathrm{nm}$ band between $100 \mathrm{~ms}$ and $2 \mathrm{~s}$, while the absorbance around $360 \mathrm{~nm}$ is still increasing with a shift of the maximum from 360 to $380 \mathrm{~nm}$ (Figure 10, inset). The absorbance at $300 \mathrm{~nm}$ is constant from $2 \mathrm{~ms}$ up to $2 \mathrm{~s}$ (Figures 9 and 10, insets). In the transient spectrum at $2 \mathrm{~s}$, which is the longest time of observations after the pulse, some additional component due to the metastable oligomers still exists between 300 and $350 \mathrm{~nm}$, that is at lower wavelength than the surface plasmon band as found by $\gamma$-radiolysis at a long time range. (The spectrum obtained with a reduction amount equivalent to the solvated electron concentration in one pulse is shown in Figure 10 for comparison.) This suggests that the cluster growth by coalescence in neat methanol is indeed much slower than in aqueous solution and that the clusters have not yet reached at $2 \mathrm{~s}$ to their final size.

In pure water the spectral, kinetical, optical, and redox properties of $\mathrm{Ag}^{0}, \mathrm{Ag}_{2}{ }^{+}$, and other small and large clusters are well established. ${ }^{16,25}$ It is also known that the optical properties of species in strong interaction with the solvent depend on its polarity. Those of silver oligomers have been obtained in some other solvents ${ }^{26}$ with which it is interesting to compare the data in methanol. The bimolecular rate constant for the reaction of $\mathrm{e}^{-}$solv with $\mathrm{Ag}^{+}$is $k_{1}=(2.6 \pm 0.6) \times 10^{10} \mathrm{M}^{-1} \mathrm{~s}^{-1}$ (instead for 


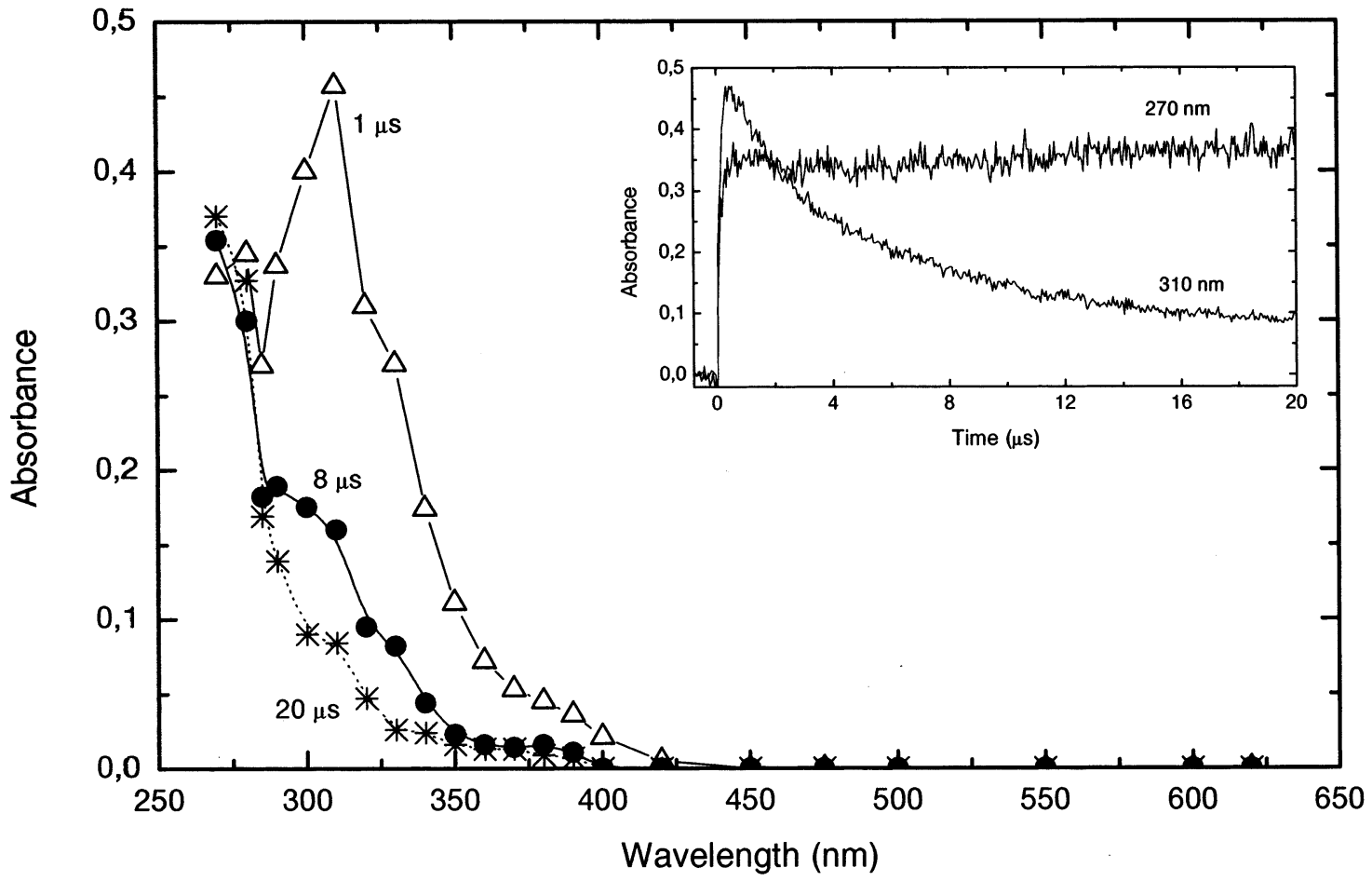

Figure 8. Transient spectra of deaerated methanolic solution of $\mathrm{AgClO}_{4} 5 \times 10^{-4} \mathrm{M}$ between 1 and $20 \mu$ s. Inset: Kinetics signals at 270 and 310 nm.

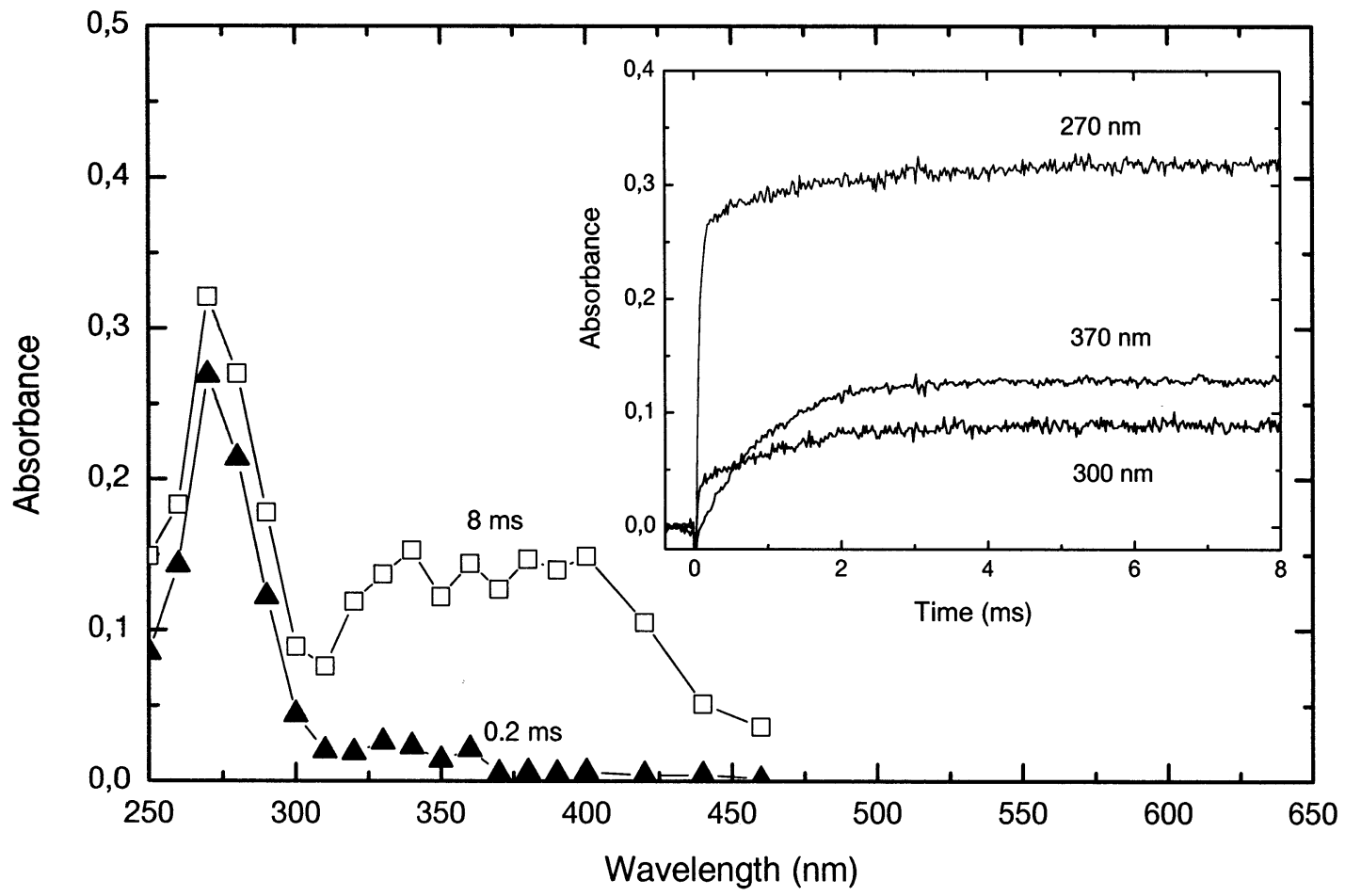

Figure 9. Transient spectra of deaerated methanolic solution of $\mathrm{AgClO}_{4} 5 \times 10^{-4} \mathrm{M}$ from 0.2 to 8 ms. Inset: Kinetics signals at 270 , 300 , and 370 nm.

example of $3.6 \times 10^{10} \mathrm{M}^{-1} \mathrm{~s}^{-1}$ in water where the reaction is diffusion-controlled). ${ }^{16}$ The mobility of the solvated electrons is indeed lower in methanol $\mu\left(\mathrm{e}^{-}\right.$solv $)=5.9 \times 10^{-4} \mathrm{~cm}^{2} \mathrm{~V}^{-1}$ $\mathrm{s}^{-1}$ than in water: $\mu\left(\mathrm{e}^{-}\right.$aq $)=1.87 \times 10^{-3} \mathrm{~cm}^{2} \mathrm{~V}^{-1} \mathrm{~s}^{-1}$, also the static dielectric constant is lower (32.6 in methanol, instead of 78 in water). In water, the absorption maximum of $\mathrm{Ag}^{0}$ is at $360 \mathrm{~nm}$. The absorption spectrum of $\mathrm{Ag}_{2}{ }^{+}$in pure water is constituted with a band located at $315 \mathrm{~nm} .{ }^{16}$ Several narrow bands at 290, 305, and $325 \mathrm{~nm}$ were also found in gelatin. ${ }^{27}$ The maxima of the absorption bands of $\mathrm{Ag}^{0}$ and $\mathrm{Ag}_{2}{ }^{+}$in methanol observed at 340 and $305 \mathrm{~nm}$, respectively, are slightly shifted to the blue relative to water as is also the absorption maximum of the solvated electron band in methanol $(630 \mathrm{~nm})$ relative to water $(715 \mathrm{~nm})$. In contrast, in less polar solvents such as ammonia or ethylenediamine where this maximum is markedly shifted to the red (1360 and $1850 \mathrm{~nm}$, respectively), ${ }^{28}$ the band maxima of $\mathrm{Ag}^{0}$ and $\mathrm{Ag}_{2}{ }^{+}$are systematically found ${ }^{25}$ at higher wavelengths than in water. In water at increasing temperature, the $\mathrm{Ag}_{2}{ }^{+}$band is also shifted to the red. ${ }^{29}$ The polarity-dependence of the silver oligomers absorption bands 


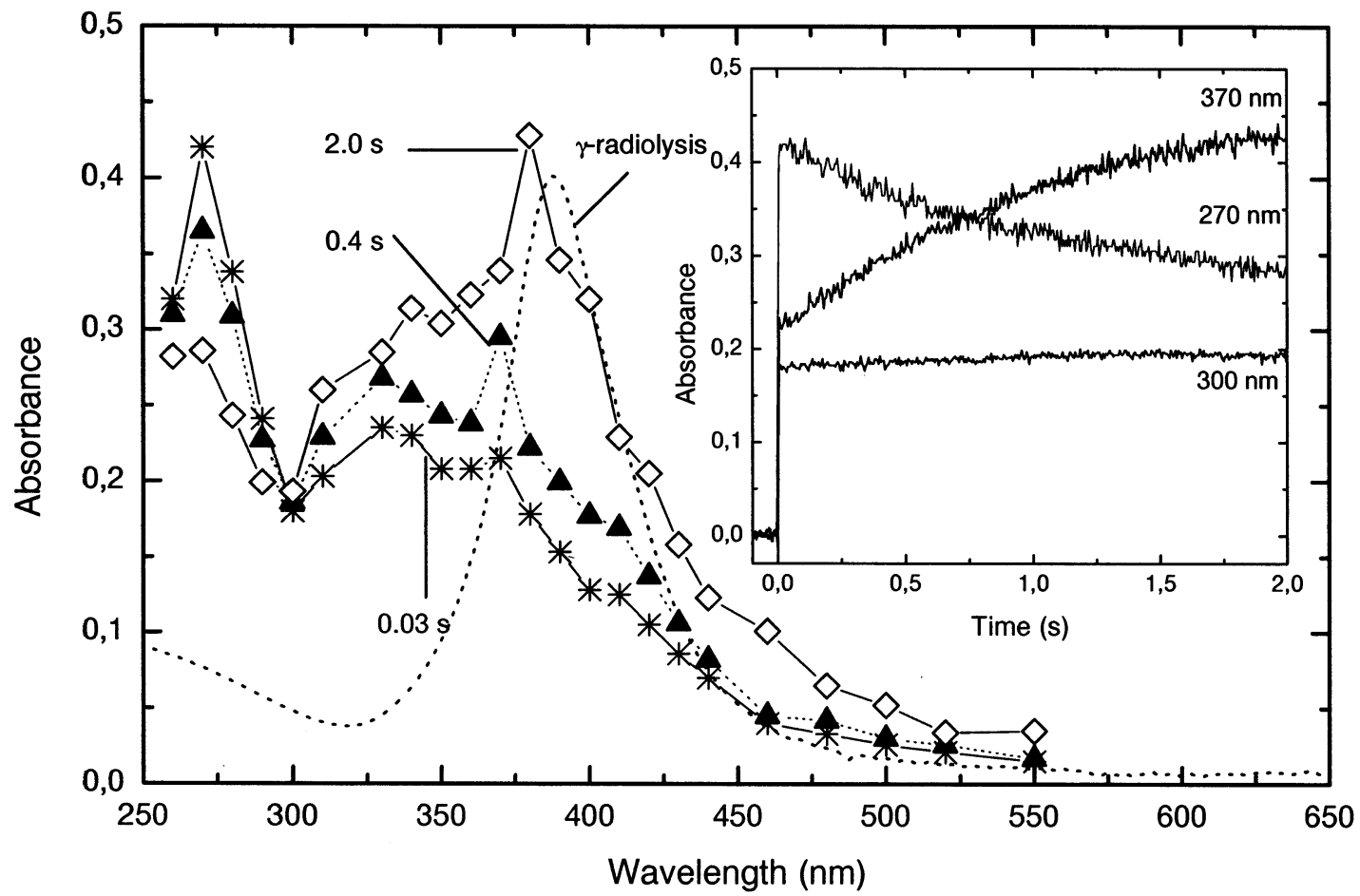

Figure 10. Transient spectra of deaerated methanolic solution of $\mathrm{AgClO}_{4} 5 \times 10^{-4} \mathrm{M}$ from 0.03 to $2 \mathrm{~s}$. Dotted line: Spectrum of the same solution, $\gamma$-irradiated with the same dose as in one pulse. Inset: Kinetics signals at 270, 300, and $370 \mathrm{~nm}$.

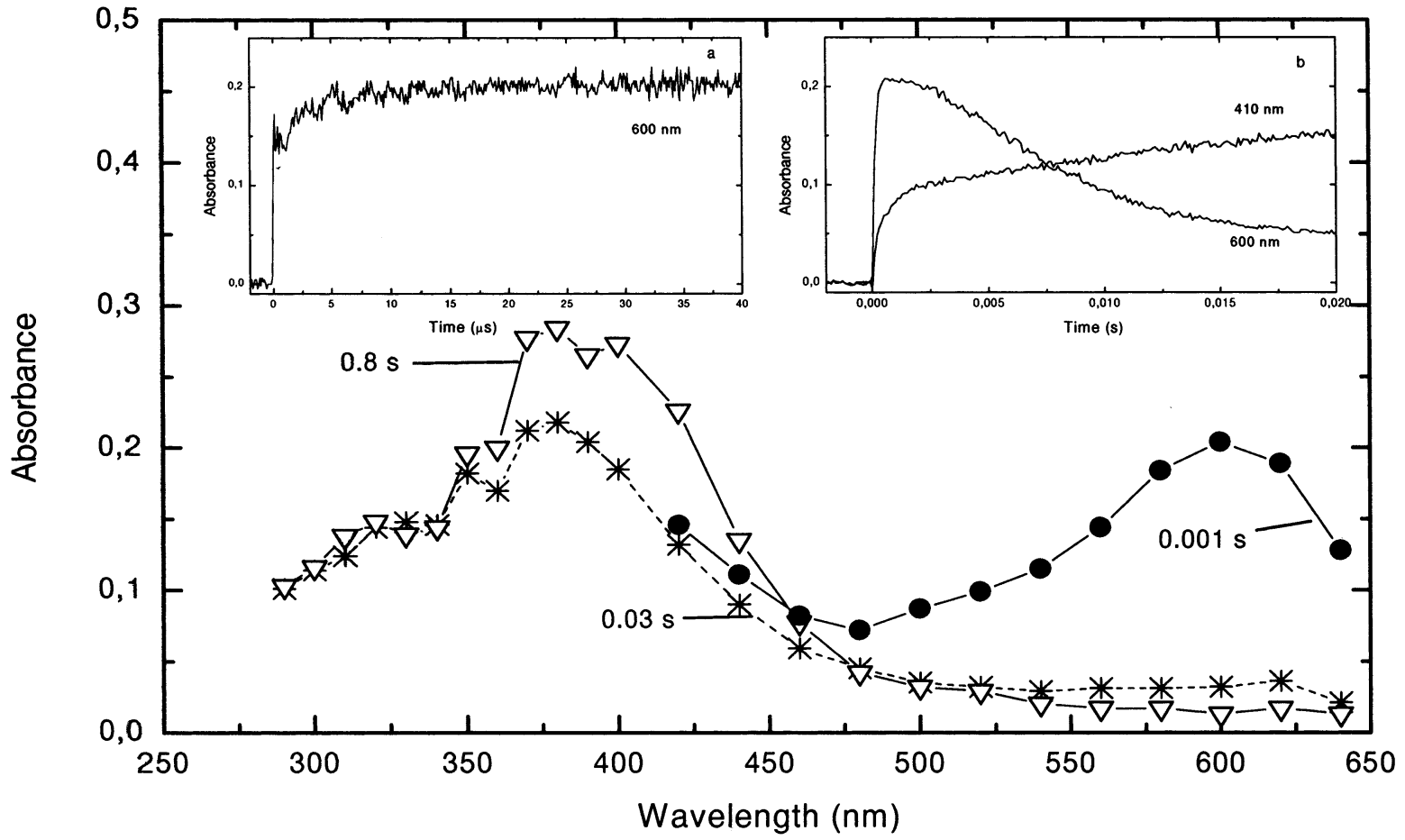

Figure 11. Transient spectra from $1 \mathrm{~ms}$ to $0.8 \mathrm{~s}$ in a deaerated mixed solution of $\mathrm{AgClO}_{4} 5 \times 10^{-4} \mathrm{M}_{\text {and }} \mathrm{MV}^{2+} 10^{-4} \mathrm{M}$ in methanol. Inset (a): time profile at $600 \mathrm{~nm}$ up to $40 \mu \mathrm{s}$. Inset (b): time profiles up to $20 \mathrm{~ms}$ at 600 and $410 \mathrm{~nm}$.

in parallel with that of the solvated electron supports the hypothesis of a partial charge transfer to the solvent (CTTS). ${ }^{30}$

In supercritical ethane and methanol as cosolvent, the positions of the absorption maxima are close to those in methanol, ${ }^{8}$ seemingly because of a clustering of this solvent around the charged oligomers.

The coalescence of oligomers in methanol is much slower than in water and is not over even at $2 \mathrm{~s}$. The oligomers seem to be of longer lifetime than in water. One explanation could be that they are complexed, either by methanol or by radiolytic products. Other similar cases of a strong influence of the ligandation on the coalescence rate have been found for other silver complexes in water. ${ }^{31-34}$ The second tentative explanation could be that there is a stronger repulsion between positively charged oligomers during the coalescence due to a lower dielectric constant.

Pulse Radiolysis Studies with Methyl Viologen. A mixture of methyl viologen $\mathrm{MV}^{2+}\left(10^{-4} \mathrm{M}\right)$ and silver salt $\left(5 \times 10^{-4}\right.$ $\mathrm{M})$ in methanol is irradiated by the same pulse in order to observe the kinetics of a possible electron transfer from silver 
oligomers to $\mathrm{MV}^{2+}$ and from $\mathrm{MV}^{+}$to charged silver clusters (Figure 11) as it was already studied in water. ${ }^{9}$ At early times (Figure 11, inset a), we observe first at $600 \mathrm{~nm}$ a fast decay within 500 ns which corresponds to the reactions of $\mathrm{e}^{-}$solv with both $\mathrm{Ag}^{+}$(reaction 1) and $\mathrm{MV}^{2+}$ (reaction 13).

$$
\mathrm{e}^{-}{ }_{\text {solv }}+\mathrm{MV}^{2+} \rightarrow \mathrm{MV}^{+} \bullet
$$

Because $\mathrm{MV}^{+} \cdot$ absorbs also around $600 \mathrm{~nm}$, the decay of the electron absorbance is partly compensated by the simultaneous increase of the $\mathrm{MV}^{+} \cdot$ absorbance. At 500 ns, when reactions 1 and 13 are over, the absorbance is only $A_{500 \mathrm{~ns}}=$ 0.12 , because the concentration of $\mathrm{MV}^{2+}$ is much lower than that of $\mathrm{Ag}^{+}$(Figure 11, inset a). The fraction of electrons yielding $\mathrm{MV}^{+\bullet}$ is thus small compared to those involved in reaction 1 . In contrast, the radicals ${ }^{\circ} \mathrm{CH}_{2} \mathrm{OH}$ do not react with $\mathrm{Ag}^{+}$but are thermodynamically able to reduce $\mathrm{MV}^{2+}$ into $\mathrm{MV}^{+} \cdot$ in competition with dimerization/disproportionation. Then, the fast decay at $600 \mathrm{~nm}$ is followed during $0.1 \mathrm{~ms}$ by a slow and important increase up to $A_{0.3 \mathrm{~ms}}=0.2$ (Figure 11, inset a), which is supposed to correspond to the transient formation of the blue color of $\mathrm{MV}^{+}$when $\gamma$-induced silver clusters are mixed with $\mathrm{MV}^{2+}$. This absorbance is stable for about $2 \mathrm{~ms}$ before decaying slowly within $0.2 \mathrm{~s}$ (Figure 11, inset b). Up to $2 \mathrm{~ms}$ around 350 $\mathrm{nm}$, the kinetics of the silver oligomer coalescence is a multistep process as without $\mathrm{MV}^{2+}$. However, the intensity of the successive bands is less, due to the partial scavenging of $\mathrm{e}^{-}$solv by $\mathrm{MV}^{2+}$ and probably also to the oxidation of small clusters by $\mathrm{MV}^{2+}$. Beyond $2 \mathrm{~ms}$, on the contrary, a second increase of the cluster absorbance around $380 \mathrm{~nm}$ is observed, with a shift of the maximum to $400 \mathrm{~nm}$ (spectrum at $0.8 \mathrm{~s}$ in Figure 11). Then the spectrum is stable.

The result is indeed confirmed by the reaction of clusters with a weaker electron acceptor such as $\mathrm{MV}^{2+}$. The small clusters generated by $\gamma$-irradiation are transformed into larger ones. Such a transformation occurs in several steps including the transient appearance and the bleaching of $\mathrm{MV}^{+} \bullet$. The same phenomenon is seen by pulse radiolysis in Figure 11. A similar mechanism has been observed by pulse radiolysis in the case of silver clusters in the presence of the $\mathrm{CN}^{-}$ligand. ${ }^{35}$

The origin of this transient production of $\mathrm{MV}^{+\bullet}$ is due to the size distribution of the clusters in the sample and to the increase of the cluster redox potential with their nuclearity. ${ }^{9}$ First, the small clusters (subcritical clusters) early formed and having a redox potential lower than that of the couple $\mathrm{MV}^{2+} / \mathrm{MV}^{+} \cdot\left(E^{\circ}\right.$ $\left(\mathrm{Ag}_{n} / \mathrm{Ag}_{n}{ }^{+}\right)<E^{\circ}\left(\mathrm{MV}^{2+} / \mathrm{MV}^{+\bullet}\right)$ are oxidized by $\mathrm{MV}^{2+}$ and produce $\mathrm{MV}^{+} \bullet$. If $n<n_{\mathrm{c}}$ (with $n_{\mathrm{c}}$ the critical nuclearity), the corrosion process occurs, and still decreases the nuclearity of the oxidized cluster. Because the potential is more negative at decreasing $n$, a cascade of corrosion reactions dissolve the subcritical clusters:

$$
\begin{gathered}
\mathrm{Ag}_{n}+\mathrm{MV}^{2+} \rightarrow \mathrm{Ag}_{n}^{+}+\mathrm{MV}^{+} \\
\mathrm{Ag}_{n}^{+} \rightarrow \mathrm{Ag}_{n-1}+\mathrm{Ag}^{+} \\
\mathrm{Ag}_{n-1}+\mathrm{MV}^{2+} \rightarrow \mathrm{Ag}_{n-1}^{+}+\mathrm{MV}^{+\bullet}
\end{gathered}
$$

This cascade of corrosion reactions (eqs 14-16) is usually slow. ${ }^{35}$ It is in competition with the cascade of coalescence reactions which results in the progressive increase of the cluster redox potential and therefore in an increasing protection against corrosion. For that reason, the mechanism (reactions 14-16) is favored by the slowness of the coalescence. Actually, corrosion was previously observed only in systems where the coalescence is also slow. ${ }^{35}$ As seen above, it is also the case in methanol. The oxidation of subcritical clusters corresponds to the increase of $\mathrm{MV}^{+}$(reactions 14 and 16) at $600 \mathrm{~nm}$ in the $0.1 \mathrm{~ms}$ range in pulse radiolysis experiments (Figure 10, inset a), and also to the formation of the transient blue color of $\mathrm{MV}^{+} \cdot$ just after the addition of $\mathrm{MV}^{2+}$ to clusters in $\gamma$-radiolysis experiments.

In the meantime, some clusters continue to coalesce and their redox potential increases in parallel with their nuclearity. The ions adsorbed at the surface of supercritical silver cluster $(n=$ $n_{\mathrm{c}}$ ), which have a redox potential more positive than that of the electron donor $\left(E^{\circ}\left(\mathrm{Ag}_{n}{ }^{+} / \mathrm{Ag}_{n}\right)>E^{\circ}\left(\mathrm{MV}^{2+} / \mathrm{MV}^{+\bullet}\right)\right)$ are not oxidized by $\mathrm{MV}^{2+}$ but reduced by $\mathrm{MV}^{+\bullet}$. Then the growing clusters again adsorb silver ions and behave by repeated reduction as nuclei of autocatalytic growth. Eventually, the few supercritical clusters are transformed into larger ones in a process similar to the photographic development process. ${ }^{9}$

$$
\begin{gathered}
\mathrm{Ag}_{n+1}^{+}+\mathrm{MV}^{+} \cdot \rightarrow \mathrm{Ag}_{n+1}+\mathrm{MV}^{2+} \\
\mathrm{Ag}_{n+1}+\mathrm{Ag}^{+} \rightarrow \mathrm{Ag}_{n+2}{ }^{+} \\
\mathrm{Ag}_{n+2}^{+}+\mathrm{MV}^{+} \rightarrow \mathrm{Ag}_{n+2}+\mathrm{MV}^{2+}
\end{gathered}
$$

Silver ions released in the corrosion cascade (reactions 1416) are adsorbed through reaction 18 and are also included in the development. This second cascade of reactions (eqs 1719) corresponds to the delayed bleaching at $600 \mathrm{~nm}$ of the $\mathrm{MV}^{+}$ blue color after $2 \mathrm{~ms}$ in the pulse radiolysis study (Figures 11 and inset b). The clusters now grow mostly by successive additions of supplementary reduced atoms (alternate reactions of electron transfer (eqs 17 and 19) and adsorption of surrounding metal ions (eq 18)), making the redox potential of $\mathrm{Ag}_{n}{ }^{+}$ more and more favorable to the electron transfer.

The results reported in Figure 6 show that both types of processes (reactions $14-17$ and reactions 17-19) are successively involved when $\mathrm{MV}^{2+}$ is added to the solution containing silver clusters. The intense component in the UV is almost completely bleached and the maximum in the visible is shifted from 385 to $420 \mathrm{~nm}$. The final spectrum corresponds to the same total concentration of silver atoms as prior $\mathrm{MV}^{2+}$ addition, but with a different size distribution. The size is now $6.5 \mathrm{~nm}$ in average, which means that each cluster contains 6.3 times more atoms than before the development. The initial amount of atoms is trusted by the upper fraction (about 16\% in atoms) of the distribution of clusters which were supercritical and which were developed to the expenses of the subcritical ones. Because they are stable in air, we conclude that for a cluster with $n$ of about a few $10^{4}$ atoms the potential is higher than $E^{\circ}\left(\mathrm{O}_{2} / \mathrm{O}_{2}{ }^{--}\right)=$ $-0.16 \mathrm{~V}_{\mathrm{NHE}}$.

$$
\begin{gathered}
E^{\circ}\left(\mathrm{CH}_{3} \mathrm{OH} / \mathrm{e}_{\text {solv }}^{-}\right)<E^{\circ}\left(\mathrm{Ag}^{+} / \mathrm{Ag}^{0}\right)< \\
E^{\circ}\left(\mathrm{HCHO}^{\circ} \mathrm{CH}_{2} \mathrm{OH}\right)<E^{\circ}\left(\mathrm{Ag}_{n}{ }^{+} / \mathrm{Ag}_{n}\right)_{n=10^{4}}< \\
E^{\circ}\left(\mathrm{MV}^{2+} / \mathrm{MV}^{+\bullet}\right)<E^{\circ}\left(\mathrm{O}_{2} / \mathrm{O}_{2}{ }^{-\bullet}\right)<E^{\circ}\left(\mathrm{Ag}_{n}{ }^{+} / \mathrm{Ag}_{n}\right)_{n=6 \times 10^{4}}
\end{gathered}
$$

However, although the initial size of the clusters is small, their oxidation by $\mathrm{MV}^{2+}$ in methanol is surprising, compared to the properties in water. It was found in water that only the clusters with less than $n_{\mathrm{c}}=5$ hydrated silver atoms could be oxidized by $\mathrm{MV}^{2+}$. In the presence of $\mathrm{CN}^{-}$ligands, nanometric silver clusters in water are also oxidized slowly by oxygen 
because the ligand lowers the redox potential of the metal particles even at rather high nuclearities. ${ }^{35}$ Silver cations are not complexed by perchlorate anions in methanol solutions. However, we should consider that some complexation phenomenon is lowering substantially the redox potential of $\mathrm{Ag}_{n}{ }^{+} / \mathrm{Ag}_{n}$ relative to the aqueous solution, thus allowing the cluster oxidation by $\mathrm{MV}^{2+}$ or $\mathrm{O}_{2}$. We propose that methanol molecules or the products issued from methanol radiolysis are playing this role of strong ligands at the surface of the particles. This explains why the critical nuclearity $n_{\mathrm{c}}$ for which $E^{\circ}\left(\mathrm{Ag}_{n}{ }^{+} / \mathrm{Ag}_{n}\right)$ is equal to $E^{\circ}\left(\mathrm{MV}^{2+} / \mathrm{MV}^{+}\right)$or $E^{\circ}\left(\mathrm{O}_{2} / \mathrm{O}_{2}{ }^{-}\right)$is much higher in methanol than in water.

\section{Conclusion}

The $\gamma$-radiolysis of the methanol-silver system offers, at least when clusters (about $10^{-7} \mathrm{M}$ ) are already formed substantially, the peculiarity of scavenging all together solvated electrons and radicals (as in water-2-propanol solutions) with a total yield $G\left(n \mathrm{Ag}_{n}\right)=12 \times 10^{-7} \mathrm{~mol} \mathrm{~J}^{-1}$, even also very slowly the molecular products ethylene glycol and formaldehyde in a postirradiation effect. On the basis of the literature data and of the yield measured in the silver system the possibility is therefore offered of deriving still unknown primary yield values, such as $G_{\text {exc }}^{0}=(2.23 \pm 0.5) \times 10^{-7} \mathrm{~mol} \mathrm{~J}^{-1}, G^{0} \mathrm{H}^{\bullet}=1.57 \times 10^{-7} \mathrm{~mol}$ $\mathrm{J}^{-1}, G_{\mathrm{H}_{2}}^{0}=G_{\mathrm{HCHO}}^{0}=0.23 \times 10^{-7} \mathrm{~mol} \mathrm{~J}^{-1}$.

The optical absorption maxima of the main band obtained by pulse radiolysis for the early species such as $\mathrm{Ag}^{0}, \mathrm{Ag}_{2}{ }^{+}$are slightly blue-shifted relative to the corresponding species in water. The plasmon band of stable clusters is also blue-shifted to $385 \mathrm{~nm}$ and is sharper with a higher extinction coefficient per atom $\epsilon\left(\mathrm{Ag}_{n}\right)_{385}=1.8 \times 10^{4} \mathrm{M}^{-1} \mathrm{~cm}^{-1}$. Under similar conditions of irradiation the cluster size is smaller $(3.5 \mathrm{~nm})$ in methanol than in water $(15 \mathrm{~nm})$.

The coalescence is much slower than in water and the redox properties are shifted toward more negative potentials to oxidation, so that a marked sensitivity to oxygen or methyl viologen $\mathrm{MV}^{2+}$ is observed whereas the clusters are stable in water. Part of the largest clusters are developed in size through reduction by $\mathrm{MV}^{+} \bullet$ as an electron relay.

Acknowledgment. A part of this work was supported by the CNRS (GDR “Acte chimique élémentaire en phase condensée") through an operating grant.

\section{References and Notes}

(1) (a) Henglein, A. Chem. Rev. 1989, 89, 1861. (b) Belloni, J.; Amblard, J.; Marignier, J. L.; Mostafavi, M. In Clusters of Atoms and Molecules; Haberland, H., Ed.; Springer-Verlag: New York, 1994; 2, p 290. (c) Henglein, A. Ber. Bunsen-Ges. Phys. Chem. 1995, 99, 903. (d) Belloni, J.; Mostafavi, M.; Remita, H.; Marignier, J. L.; Delcourt, M. O. New J. Chem. 1998, 22, 1239.

(2) Clusters and colloids; Schmid, G., Ed.; VCH: Weinheim, 1994
(3) Belloni, J.; Mostafavi, M. In Metal Clusters in Chemistry; Braunstein, P., Oro, L. A., Raithby, P. R., Eds.; Wiley: New York, 1999; p 1213. (authors) In Radiation Chemistry Present Status and Future Trends; Jonah, C. D., Rao, B. S. M., Eds.; Elsevier: Amsterdam, 2001; p 411.

(4) Liz-Marzan, L. M.; Lado-Tourino, I. Langmuir 1996, 12, 3585.

(5) Huang, Z. Y.; Mills, G.; Hajek, B. J. Phys. Chem. 1993, 97, 11542.

(6) Buxton, G. V.; Dainton, F. S.; Hammerli, M. Trans. Faraday Soc. 1967, 63, 1191 .

(7) Underwood, S.; Mulvaney, P. Langmuir 1994, 10, 3427.

(8) Dimitrijevic, N. M.; Bartels, D. M.; Jonah, C. D.; Takahashi, K.; Rajh, T. J. Phys. Chem. B 2001, 105, 954.

(9) Mostafavi, M.; Marignier, J. L.; Amblard, J.; Belloni, J. Radiat. Phys. Chem. 1989, 34, 605.

(10) Ellison, D. H.; Salmon, G. A.; Wilkinson, F. Proc. R. Soc. London 1972, A328, 23.

(11) Baxendale, J. H.; Wardman, P. The Radiolysis of Methanol; National Bureau of Standards, NSRDS-NBS 54, U.S. Government Printing Office: Washington, DC, 1975.

(12) Kalachandra, S.; Farhataziz; Foyt, D. C. Radiat. Phys. Chem. 1983, 21,509 .

(13) Ferradini, C.; Jay-Gérin, J. P. Radiat. Phys. Chem. 1996, 48, 473

(14) Belloni, J.; Billiau, F.; Delaire, J.; Delcourt, M. O.; Marignier, J. L. Radiat. Phys. Chem. 1983, $21,177$.

(15) Schwarz, H. A.; Dodson R. W. J. Phys. Chem. 1989, 93, 409.

(16) Henglein, A.; Tausch-Treml, R. J. Colloid Interface Sci. 1981, 80 , 84.

(17) Rzad, S. J.; Fendler, J. H. J. Chem. Phys. 1970, 52, 5395.

(18) Hunt, J. W.; Lam, K. Y.; Chase, W. J. Radiation Research, Biomedical, Chemical and Physical Perspectives; Nygaard, O. F., Adler, H. I., Sinclair, W. K., Eds.; Academic Press: New York, 1975; p 345.

(19) Getoff, N.; Ritter, A.; Schwörer, F. J. Chem. Soc., Faraday Trans. $1 \mathbf{1 9 8 3}, 79,2389$.

(20) (a) Baxendale, J. H.; Wardman, P. J. Chem. Soc., Faraday Trans. 1 1973, 69, 584. (b) Hentz, R. R.; Kenney-Wallace, G. J. Phys. Chem. 1974, 78, 514.

(21) Zhang, G.; Thomas, J. K. J. Phys. Chem. 1994, 98, 11714.

(22) Sauer, M. C., Jr.; Arai, S.; Dorfman, L. J. Chem. Phys. 1965, 42 708.

(23) (a) Getoff, N.; Ritter, A.; Schwörer, F.; Bayer, P. Radiat. Phys. Chem. 1992, 39, 177. (b) Getoff, N.; Ritter, A.; Schwörer, F.; Bayer, P. Radiat. Phys. Chem. 1993, 41, 797.

(24) Jha, K. N.; Bolton, G. L.; Freeman, G. R. J. Phys. Chem. 1972, $76,3876$.

(25) Ershov, B. G.; Janata, E.; Henglein, A.; Fojtik, A. J. Phys. Chem. 1993, 97, 4589

(26) Belloni, J.; Delcourt, M. O.; Marignier, J. L.; Amblard, J. In Radiation Chemistry; Hedwig, P., Nyikos, L., Schiller, R., Eds.; Akademia Kiado: Budapest, 1987; p 89.

(27) Kapoor, S.; Lawless, D.; Kennepohl, P.; Meisel, D.; Serpone, N. Langmuir 1994, 10, 3018.

(28) Belloni, J.; Marignier, J. L. Radiat. Phys. Chem. 1989, 34, 157.

(29) Mostafavi, M.; Lin, Mingzhang; Wu, Guozhong; Katsumura, Y.; Muroya, Y. J. Phys. Chem. A, in press.

(30) Belloni, J.; Khatouri, J.; Mostafavi, M.; Amblard, J. In Ultrafast reaction dynamics and solvent effects; Rossky, P. J., Gauduel, Y., Eds.; American Institute of Physics: Woodbury, NY, 1993; p 541.

(31) Remita, S.; Mostafavi, M.; Delcourt, M. O. Radiat. Phys. Chem. 1996, 47, 275.

(32) Remita, S.; Archirel, P.; Mostafavi, M. J. Phys. Chem. 1995, 99, 13198.

(33) Texier, I.; Remita, S.; Archirel, P.; Mostafavi, M. J. Phys. Chem. 1996, 100, 12472

(34) Remita, S.; Mostafavi, M.; Delcourt, M. O. J. Phys. Chem. 1996, 100, 10187.

(35) de Cointet, C.; Mostafavi, M.; Khatouri, J.; Belloni, J. J. Phys. Chem. 1997, 101, 3512. 